Portland State University

PDXScholar

Spring 7-19-2013

\title{
Learning to Adapt: Online Social Science Instruction in Higher Education
}

Patrick Steven Smith

Portland State University

Follow this and additional works at: https://pdxscholar.library.pdx.edu/open_access_etds

Part of the Educational Methods Commons, Higher Education Commons, and the Online and Distance Education Commons

Let us know how access to this document benefits you.

\section{Recommended Citation}

Smith, Patrick Steven, "Learning to Adapt: Online Social Science Instruction in Higher Education" (2013). Dissertations and Theses. Paper 1089.

https://doi.org/10.15760/etd.1089

This Thesis is brought to you for free and open access. It has been accepted for inclusion in Dissertations and Theses by an authorized administrator of PDXScholar. Please contact us if we can make this document more accessible: pdxscholar@pdx.edu. 
Learning to Adapt: Online Social Science Instruction in Higher Education

by

Patrick Steven Smith

A thesis submitted in partial fulfillment of the requirements for the degree of

\author{
Master of Science \\ in \\ Sociology
}

Thesis Committee:

Daniel Sullivan, Chair

Robert Liebman

Martha Balshem

Portland State University

2013 
C 2013 Patrick Steven Smith 


\begin{abstract}
Online learning is a rapidly growing phenomenon in post-secondary education.

Institutions of higher learning have embraced online learning for its perceived merits, but without the consideration of how instructors deal with this different learning medium. Little is known of the extent to which different disciplines are suited to the online medium; this is pertinent to disciplines that rely on spontaneous in-person discussion. Furthermore, as colleges continue to invest heavily in online learning, instructors who only possess face-to-face teaching experience may begin teaching online. This poses a pedagogical challenge for instructors who are unfamiliar with the medium. This qualitative, in-depth interview study with ten social science instructors elucidates the process of transition from face-to-face teaching to online teaching. Through grounded analysis, a few key themes emerged. Respondents explain that teaching in the online classroom is qualitatively different from teaching in-person. The asynchronisity of the online classroom - which means students do not "meet", discuss, or learn at the same time - is a subtle yet significant difference between the two mediums. The asynchronous classroom means instructors relinquish control of when and where students will engage in study and discussion, and this requires students to have especially high self-regulatory skills. Respondents also explained that their online courses were several times larger than their in-person ones, with some courses allowing over twice as many students as an in-person course. Consequently, instructors must find new ways to approach teaching in the online medium. This pitfall of relying on old, obsolete methods in the online medium can be avoided if instructors are provided with the peer and pedagogical support of their professional peers, and access to teaching assistants to manage the greater time commitment of teaching online. In order to have a positive experience, online teachers must be willing to take on an intellectual challenge that may defy how they perceive themselves and their role in higher education. If instructors are open to a new intellectual
\end{abstract}


challenge and possess the proper resources, they will become committed to teaching online and perceive the advantages of the medium to outweigh the disadvantages. 


\section{DEDICATION}

To my parents, Steve and Colleen. With your encouragement, I aimed for the stars and landed on the moon. Where to now? 


\section{ACKNOWLEDGEMENTS}

I would first like to thank the online instructors who participated in this study. Your willingness to share your stories and opinions has enabled me to shed light on your understudied yet growing - population. Next, I would like to thank my esteemed committee members, Doctors Daniel Sullivan, Bob Liebman, and Martha Balshem. You all played a key role in the development of this thesis, and what I took away from your courses and our conversations helped and will continue to help me grow as a researcher and a sociologist. Frankly, all other professors need to take notes from these three instructors. Daniel, Bob, and Martha are the most thoughtful and wise intellectuals I have ever had the fortune of knowing. In particular, I need to thank Bob Liebman, my assistantship supervisor, for being my mentor in my time here at Portland State. Your boundless passion for teaching and relentless encouragement helped me grow to a degree that these words cannot describe, and I will strive to hold myself to your standard of fervent tenacity in all of my future pursuits.

I also need to thank Doctor Pete Collier for giving me the idea to study this topic. Bahar Jaberi, the department coordinator, deserves mention here as well. She was an important source of both practical assistance and friendship during my time in this program. All of my cohort members were critical to the completion of this thesis. In particular, sharing conversations and libations with, Aaron, April, Daniel, Elisabeth, Kym, and Jeff helped me to define, defend, clarify, and reform my arguments. I must also thank King Tubby for providing the soundtrack while writing my thesis. Finally, I must acknowledge my sisters, Meagan and Lindsay, and my brother, Josh. Without your insistence that I did belong in this Master's program - that I was not, as I believed, an imposter - I would never had made it this far. Your unconditional faith in me inspires me to persist in doing great things. 


\section{TABLE OF CONTENTS}

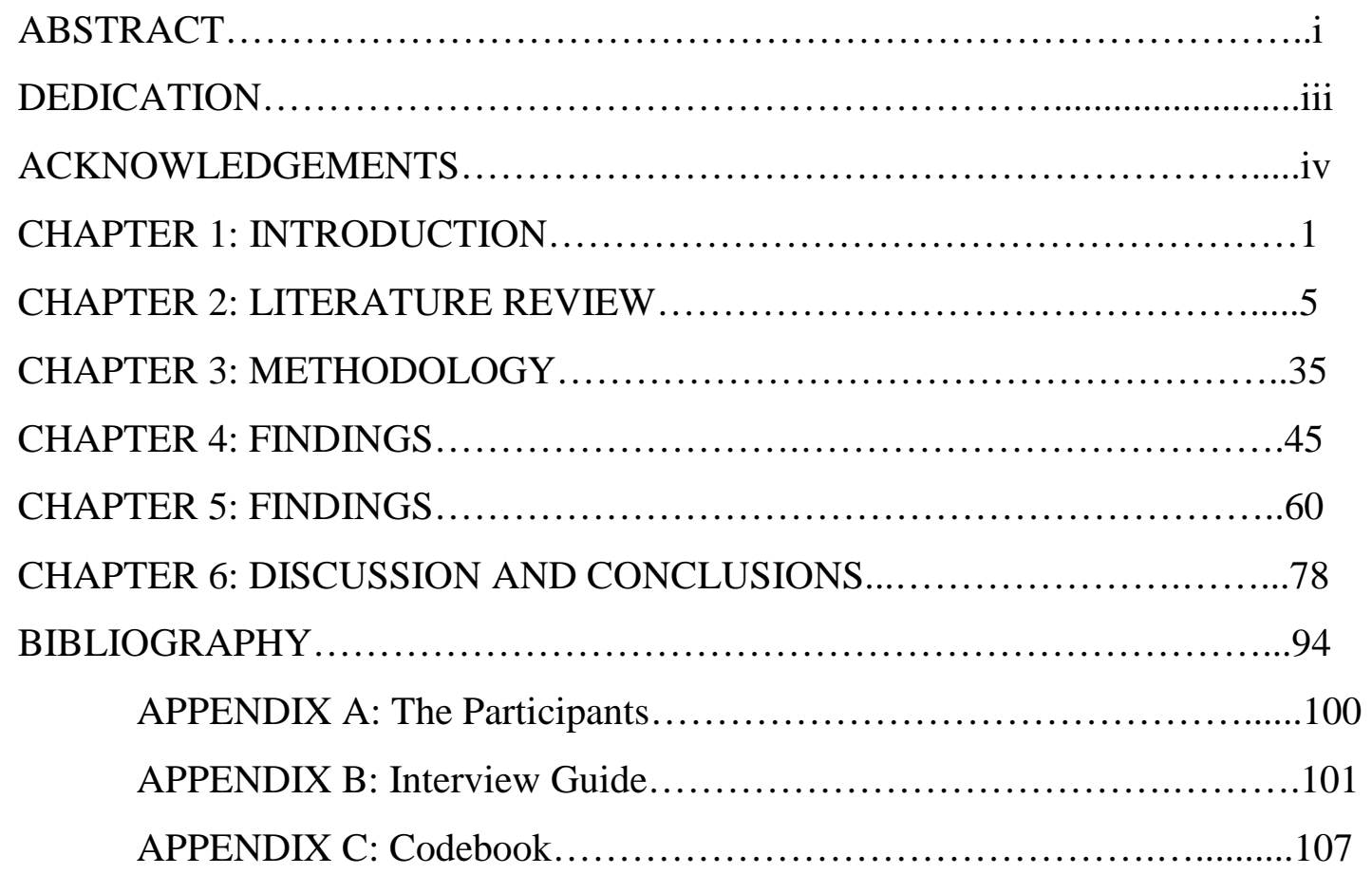




\section{CHAPTER 1: INTRODUCTION}

Over a quarter of all students enrolled in the U.S. university system now take at least one online course (Allen and Seaman, 2010:1). Enrollment in online college courses has grown at a rate of 16 percent more per year than overall higher education enrollment, a trend that researchers expect to continue (Allen and Seaman, 2010:1). This trend is an interesting dilemma for university professors because an online course - one in which the course never meets face-to-face and only over a virtual network - is distinct from an inperson course.

Online learning is a form of "distance learning". Beginning in the mid-1970's, universities began offering distance learning via teleconferencing, e-mail, and traditional mail; students would use mail correspondence and occasional telephony to complete their distance courses. With the emergence of new computing technology came new changes. 1981 marked the emergence of the first fully online course, followed by the first online degree program in 1986 offered by the University of Phoenix. Finally, in 1996, online education became a fixture in higher education, and began to resemble what it looks like today (Harasim 2000). Portland State University has been offering online courses since 1996, but recently announced plans to invest heavily in the medium (Portland State Fact Sheet). Thus, this trend has been a long time coming, and represents a fundamental shift in higher education.

Harasim (2000) notes the two mediums are different in the following five ways:

1) Communication is many-to-many (rather than one-to-many as in a lecture), 2) learning 
happens any place and 3) any time the student chooses, 4) communication is text-based (rather than speech-based), and 5) communication is mediated by a computer. Most agree upon these five distinctions, but that is where the consensus ends. In the discussion of teaching online, one controversial issue has been the question of whether or not the online classroom can be of the same quality as the in-person one, and how (or if) the role of the professor is changed as a result of the aforementioned five distinctions.

Central to this controversial conversation of teaching online is the question of classroom discussion. Instructors must decide how to transmit knowledge to students. How an instructor chooses to structure student interaction with content is known as pedagogy (Bernstein 1986). Colloquially, it is the art of teaching. Social science instructors often make the similar pedagogical choice of using classroom discussion, and this stands a challenge in the online format. On the one hand, some researchers argue that the online medium of teaching and discussion facilitation is of equal or greater quality than the in-person one, and thus will provide an instructor with a positive experience (Russell 1997; Persell 2004; Jaffee 1997). In the online medium, observable markers such as age, race, and gender cannot be used to assign stereotypes (McShane 2004), the anonymity of discussion boards causes some students to participate where they otherwise would not (Hampton and Wellman 2001), the discussion is more equitable because every student can participate rather than a vocal few (Jaffee 1997), and because students have more time to reflect leading to perhaps more thoughtful discussion (Baglione and Nastanski 2007). On the other hand, teaching online may pose as a difficult and 
transformative experience for instructors; some contend that the online classroom particularly online discussion - is not well suited for all students and may require assistance to students on an individual basis (Andrews and Haythornthwaite 2007), has no established pedagogy (Levine and Sun 2002), is without spontaneous interaction that some find important to teaching and leading discussions (Kanuka, Collett, and Caswell 2002), is not a proper environment to discuss abstract concepts that are central to social sciences (Clark-Ibanez and Scott 2008), and may be up to 50\% more work for online teachers because everything must be written down, rather than spoken (Conceicao 2006) . Some (Smith, Ferguson, and Caris 2002; Major 2010) even maintain that the online classroom changes the faculty role from instructor to facilitator, a decentralization of teaching authority that may be problematic for those unwilling to relinquish control.

My own view is that the quality of the online teacher's experience depends on the level of support they receive from their peers and the administration, the instructor's awareness of effective online teaching strategies and the commitment to online learning to follow such strategies. Because faculty buy-in is critical for the further adoption of online course delivery, a better understanding of faculty experiences with online pedagogy in comparison to a face-to-face pedagogy is crucial. Instructors are the most qualified to evaluate educational outcomes, and - because these outcomes are of the university's primary concern - faculty perspectives must represent a substantial part of the conversation about online education. However, my intention is not to address whether or not learning and teaching online is high quality or of value to universities. Rather, I 
intend to explore how the distinct nature of the online classroom influences how online instructors view themselves, their teaching strategies, and their role in higher education.

To meet this end, I ask:

1. How do PSU social science instructors perceive teaching and learning - namely, delivering information, coaching writing skills, and facilitating discussion - inperson and online?

2. What factors determine the degree to which PSU social science instructors are committed to teaching online?

3. Does teaching online influence the way in which PSU social science instructors construct meaning about themselves and their role in higher education?

The next chapter will review the theoretical and empirical research regarding the importance of classroom discussion and then transition to a discussion of the advantages and disadvantages of discussion in the online format. The third chapter introduces the methodology: a qualitative analysis of 10 in-depth interviews with online social science instructors at Portland State University in Portland, Oregon. The fourth and fifth chapters detail the findings from this research. The final chapter is both a discussion of the findings and of implications, limitations and areas for future research. 


\section{CHAPTER 2: LITERATURE REVIEW}

Although extensive research on the online learner's experience has been conducted, less is known about how teachers experience the online classroom. Much of the empirical work that does exist on professors' perceptions consists of personal observations from online professors themselves (Jaffee 1997; Persell 2004; Clark-Ibanez \& Scott 2008). Major (2010) explains that quantitative research exploring teaching online has elucidated faculty perceptions of benefits and drawbacks of the medium, while qualitative research has focused on the general experience of teaching online, but without the consideration of 1) specific disciplines and 2) including in the sample both new recruits and experts of online instruction. There is much, therefore, to be discovered about how college professors in discussion-heavy disciplines such as the social sciences understand, experience and utilize virtual space in the gradual process of adaptation. This can contribute to cumulative knowledge on the subject of teaching online. Relevant literature suggests that the experiences of online teachers will likely be affected by the nature of online interaction, the level of support - technical and social - provided to the online teacher, and the extent to which an online instructor is willing to adapt his or her role and pedagogies to the online classroom.

Allen and Seaman's (2009) quantitative survey study of university administrators provides a lens with which to approach respondents in the current study. These researchers found that an overwhelming majority of their respondents (81 percent) consider online education "critical to the long-term strategy of [their] institution," without 
speaking to the quality of online learning (2009:10). Yet, they indicate "the upward pressure to offer more online courses... [may lead] to increased 'push back' among...faculty," (12) which further complicates the institutional implementation of online courses. Although their quantitative findings indicated that university administrators believe faculty are reluctant to buy-in to teaching online, they acknowledge that this does not adequately explain how faculty understand and experience online learning. Indeed, it is clear that administrators know very little about the experiences and views of those who must deliver and manage online courses. Thus, it is critical to gather an inclusive understanding of both positive and negative evaluations of teaching online. In particular, this chapter will focus on varying perspectives of inperson and online classroom discussion - a hallmark of social science disciplines.

\section{Promoting Engagement and Higher Learning through Discussion}

Students interact with course content in many ways; independent reading, essays, and group presentations are some examples, but discussion is one of the most common ways student interaction with content is structured. Classroom discussion is a tried and true pedagogical method that is the hallmark of the social science disciplines. Scholars characterize discussion as an emergent exchange of ideas and a shared creation of knowledge via spontaneous interaction (Clark-Ibanez and Scott 2008). Discussion can help students and improve learning outcomes in the following ways: 
- Exploring topics with peers will clarify points of confusion that are in the peripheral (Egle, Navarre, and Nixon 2011).

- Discussion helps solidify concepts by forcing students to "defend, clarify, elaborate and reform" her or his understandings, which leads to greater learning outcomes (Clark-Ibanez and Scott 2008).

- Peer collaboration encourages imaginative learning and accommodates various learning styles (Clark-Ibanez and Scott 2008).

Some of the face-to-face (F2F) discussion-generating techniques include forming small groups to encourage inter-student interaction, or calling on students by name for a response (Egle, Navarre, and Nixon 2011). A key discussion-generating technique in the online format is to break a course down into several term-long small groups and provide each group with a teaching assistant discussion facilitator (Cacciamani et al. 2012). This provides the students a familiar group of peers with whom they may build rapport. Discussion-based teaching is often at the heart of the social sciences because social theory is negotiable; the social sciences are often a "living force" that necessitates "an energetic exchange in which ideas come alive," (Egle, Navarre, and Nixon 2011:13). Furthermore, some research has found that a socio-cognitive conflict drawn out from discussion- that is, the presence of multiple answers to the same problem - leads to engagement and learning when a student considers perspectives different from his or her own (Doise and Mugny 1984). This also shows students that there is more than one 
possible way to explain and understand social phenomena. Thus, in the dynamic disciplines of the social sciences, discussion is a critical element to successful learning.

The teaching strategies employed by online teachers vary considerably, with some simply transposing F2F lectures into an online format, and with others adapting to the unique flexibility of teaching online. However, it is without question that facilitating online discussion is an unfamiliar challenge for instructors new to the online medium. It follows that the strategies pursued by an online teacher will affect his or her experience with the online classroom. Research that has focused on online teaching strategies suggests that instructors should avoid transferring their F2F lecture to an online course (Clark-Ibanez and Scott 2008; Norton and Hathaway 2008; Driscoll et al. 2012). However, despite research suggesting they do otherwise, many online instructors forgo online discussions. In a comparison of online teaching strategies, Norton and Hathaway (2008) find that many online teachers "emphasize the passing along of information rather than promoting learning," (476). Norton and Hathaway (2008) explain that teachers teach how they were taught, and as a result, often employ the "deposit" model of teaching in an online classroom because they lack an understanding of how to facilitate quality discussion online. In other words, they provide online students with an electronic form of lecture in order to impart knowledge to them because they lack the awareness of how to do things differently. This results in an overemphasis on content - the "product" - and an under-emphasis on student comprehension and learning - the "customer". The teacher-led 
deposit model is less effective online (Major 2010) and, if employed, could lead to a negative experience teaching online.

Thus, for social science instructors, a primary hurdle is facilitating inter-student discussion, and this is particularly challenging online. Discussion is fundamental to the learning process, as critical thinking happens best "through interaction and discussion with peers," (Clark-Ibanez and Scott 2008, 38). Collaboration amongst peers is also a critical tool in reinforcing knowledge. Clark-Ibanez and Scott (2008) compared lecture and discussion pedagogies and found that a mere 5 percent of information was retained from lecture-based teaching. Retention rates increased considerably with the use of learning by doing; retention was highest when teaching others because collaboration leads to engagement and higher learning. It follows, then, that it is critical to foster interlearner interaction and encourage students to teach and learn from one another.

\section{Computer-Mediated Communication - Any Place, Any Time, Text-Based}

\section{Interaction}

An examination of the nature of online interaction is necessary to pursue an understanding of professors' experiences teaching and facilitating discussion online. This section therefore begins with an evaluation of computer-mediated communication before moving on to the other distinct aspects of online discussion and learning.

Computer-mediated communication (CMC) can be similar to face-to-face (F2F) communication when it is synchronous (or "live") as in the case of a chat room. 
However, CMC (especially online learning) often is asynchronous; e-mails and discussion board posts, for example, are not live conversations, but rather are carried out at the time and place chosen by the individuals involved. Thus, $\mathrm{CMC}$ is distinct from face-to-face F2F communication when it is disembodied and asynchronous; CMC removes many of the physical indicators on which individuals typically rely, but it allows interaction to take place anywhere and at any time. As a result, $\mathrm{CMC}$ boasts some advantages over F2F discussion. Many advantages of CMC have been empirically demonstrated, but the most prominent ones are outlined below.

\section{Advantages of CMC}

\section{Reduced Anxiety}

One key advantage of computer-mediated learning is its anonymity. Disembodied interaction may reduce the anxiety that many people associate with F2F interaction, which can lead to more revealing and meaningful exchanges; online communication reduces social anxiety and causes some to interact where they otherwise would have been inhibited (Smith, Ferguson, and Caris 2002). In a qualitative study of the experiences of 22 online instructors with web-based teaching, instructors reported great satisfaction with online discussions because most every student produced rich posts, whereas getting every student to engage in a F2F discussion is much more challenging. Respondents reported having to put little effort forth to encourage students to discuss online; online students seemed to want to participate in the online discussion, whereas this did not seem to be the 
case in their in-person courses (Smith, Ferguson, and Caris 2002). However, like any small convenience sample such as this, these results are not necessarily transferable to all online instructors. Consequently, other aspects of asynchronous CMC must be considered.

\section{24/7 Connectivity}

The ubiquitous connectivity and lack of physical presence enabled by computermediated communication may facilitate more contact than would be possible in a F2F setting. Hampton and Wellman (2001) interviewed residents of a community ("Netville") prior to the acquisition of internet access, and then again after the community gained internet access. Respondents in their qualitative study reported an increased level of interaction with their community members as a result of $24 / 7$ connectivity via the internet (Hampton and Wellman 2001). Although this finding derives from a methodologically sound study, there is room for skepticism because the Netville residents had a particular disposition: respondents placed the same value on online interaction as they did F2F interaction. The fact that $\mathrm{CMC}$ provides greater access to others is a point of consensus, but a greater opportunity for interaction does not mean those interactions will necessarily be of the same nature as in-person interactions.

\section{Increased Personal Responsibility}

Increased access to others via CMC adds "layers of connectivity and opportunity" for interaction that supersede F2F interaction (Haythornthwaite \& Wellman 2002:8); 
computer-mediated communication makes those in a social network available to one another all of the time. The time and place at which interaction takes place is dictated by individual choice, and in this way $\mathrm{CMC}$ interaction is distinct. Haythornthwaite and Wellman (2002) argue that the internet has created a "networked society" on and off the internet, in which people have a "networked individualism"; people have networks which are "diffuse, sparsely knit, with...overlapping spatial boundaries...People now go through the day...in a variety of narrowly defined relationships with changing sets of network members," that are self-selected (32-33). The norms and mores of interaction are transforming because of these narrowly defined relationships in which the social horizon is increasingly focused on the individual in online communication, rather than on the collective as in F2F communication. In other words, CMC creates a highly personalizable reality. This involves a shift away from geographically defined communities and towards "individualized interpersonal ties" that are unique and specific to the online environment (Haythornthwaite \& Wellman 2002:34). It is possible that the departure away from placebased community and towards online community networks will occur as technology becomes increasingly personalizable and, most importantly, portable and accessible (Haythornthwaite \& Wellman 2002). Similarly, the online classroom provides students with a highly individualized and personalized learning experience because learning happens asynchronously; students choose when and where to be a student, rather than the synchronous F2F classroom in which the instructor makes those decisions. Thus, learning 
online is more independent than learning in-person, and may be more suited to preparing students for the responsibilities of the "real world" of adult work (Major 2010).

\section{Asynchronous Interaction}

Much of computer-mediated communication happens asynchronously, as opposed to the fundamentally real-time nature of F2F interaction. Wellman, Boase and Chen (2002) argue that the ubiquitous connectivity and portability of CMC technologies has created a new realm of personal choices concerning when, where, and with whom to interact. Individuals no longer must be "called away" to interact with others asynchronously; in the case of online learning, individuals no longer must travel to a physical classroom. Instead, learning happens anywhere the individual has internet access, and in this way is personalized (Wellman, Boase, and Chen 2002:10-1). This reduction of time constraints has some distinct advantages. In a F2F setting, for example, only a few students can give an answer to each question posed by the instructor; on an asynchronous discussion board, every student can be expected to answer the instructor's inquiry (Jaffee 1997). Thus, asynchronous discussion may be more beneficial for the entire population of a course, rather than for the handful of students who routinely participate in a F2F course discussion.

\section{Disadvantages of CMC}

Aside from the potential advantages of computer-mediated education, there are some pitfalls of CMC. The loss of physicality between interacting individuals removes 
sensory, expressive, and nonverbal aspects of communication that many instructors value (Major 2010).

\section{Text-Based Interaction}

One subtle yet significant characteristic of text-based interaction is its permanence. McLuhan (1964) famously said that the "medium is the message"; MacDougall (2005), a practitioner of McLuhan's theory, explains that the medium in which communication is transmitted is as significant as the content of the interaction itself. In the case of asynchronous text-based communication, interaction becomes increasingly self-aware and self-referential because the content of the interaction is archived; "in the textual format, linguistic symbols linger; in the spoken, they fade," (MacDougall 2005, 585). MacDougall's analysis implies the tenets of symbolic interactionism because he is arguing that the self is constructed from the outside-in. In the online environment, the heightening of self-awareness and self-referentiality and reduction of spontaneous interaction may force the instructor to adapt his or her role accordingly.

Major (2010) makes similar conclusions in her meta-analysis of nine qualitative studies on teaching online. Across all nine studies and 117 faculty members, she finds that the text-based, any time, any place nature of online teaching requires faculty to reconsider who they are as teachers. Furthermore, communication in an online course is many-to-many, rather than one-to-many (Harasim 2000). In other words, discussion posts 
can be written and read by everyone, which is different than, for example, the one-to-one nature of an essay submitted by a student to a professor. This reduces or eliminates the traditional need for central leadership. An asynchronous discussion board eliminates the stand-and-deliver style of teaching that contemporary professors may be accustomed to. Instead, online faculty describe themselves as role models or facilitators of learning, rather than as teachers (Major 2010). This is in part because online students interact with content rather than with people, a process Major (2010) calls "informating". In other words, online instructors answer questions about content and guide students' understanding rather than deliver information and lead a discussion (as in a F2F lecture). Major's (2010) key finding in her meta-analysis is that this transition to teaching online was problematic for those unwilling to relinquish control, and is signified by "nostalgia for the previous, more carefree position," (Major 2010, 2171).

\section{Asynchronous Interaction}

An asynchronous discussion is a rhetorical space because it is socially constructed. Asynchronous networks are therefore constructed and reconstructed by the practices and values of a particular cultural milieu (Andrews and Haythornthwaite 2007:5). The cultural milieu of the collegiate online classroom- in which text-based discussion supplants face-to-face dialogue - may affect how professors and students understand the utility of this pedagogy; in a sense, technology in education shapes how students learn because it interacts with the "cognitive processes that underpin learning," (Andrews and Haythornthwaite 2007:5). In other words, it changes how students know 
how to know. This is especially pertinent to classroom environments in which much of the learning happens between individuals (such as a discussion-laden social science course) rather than between an individual and a text. Courses in which discussion is a central component may be less suited to the online world. In a quantitative learner-centric study, Faux and Black-Hughes (2000) found that "41.7 percent of the students [in the sample] did not feel comfortable learning from the internet in their online course." This study looked at one history course that was discussion-heavy. Students wanted more instructor feedback and auditory stimulation; they wanted to "listen to, rather than read about, historical material," (98). It is possible that the online platform may not be an ideal environment for critical discourse that is so central to disciplines such as the social sciences. However, because this study gathered data from only one course, the results are somewhat anecdotal and in need of further study.

The inherently asynchronous nature of online learning must be incorporated into pedagogy in order to achieve successful learning outcomes, and this requires a greater time commitment for instructors. With some exceptions, instructors address student needs individually in an online course - through one-on-one correspondence via e-mail or messaging - rather than collectively in a F2F course. Indeed, some research has found that the diffuse time commitment of the online classroom is problematic for online teachers, as the "convenience of going to school anytime and anywhere entails greater responsibility from educators to deliver quality instruction," (Lao and Gonzales 2005, 472). An online course also requires everything to be written down, a task which is 
unnecessary in a F2F course in which most communication is spoken (Conceicao 2006). In this way, online instruction may require greater input of time for teachers because they need to cater to the individualized needs and correspondence of each student. Teachers are expected to be available for inquiry at all times, much like the expectation for individuals in an online society to be available for interaction all of the time. The literature lacks a solution to this hurdle.

One key disadvantage in the asynchronous online classroom is the loss of spontaneity. Kanuka, Collett, and Caswell (2002) find that many grievances with teaching online dissipate over time, with the exception of coping with the loss of "illustrative spontaneity": the notion that learning is emergent and flexible, and that teachers evaluate nonverbal cues from students in order to assess what concepts need elaboration. Instructors felt that online environments failed to compensate for the nonverbal cues that provide instant feedback for students and teachers alike. Thus, by creating a highly structured and asynchronous learning environment, some degree of spontaneity (which the interview subjects had relied on heavily in their F2F courses) was lost (Kanuka, Collett, and Caswell 2002). This is one key disadvantage that - at least in terms of text-based online courses - cannot be overcome. The struggle for a balance between flexibility and structure surfaced as the largest hurdle when transitioning from face-to-face to online course delivery. Specifically, the need to balance structure and discussion was reported as particularly challenging for the online teachers in this study. 
Flexibility is here operationalized as dynamism; respondents explained that online courses are planned in advanced and are not "as flexible as handouts or notes on a chalkboard". (Kanuka, Collett, and Caswell 2002:160). Online faculty are faced with the challenge of balancing the inherently structured nature of online courses with the need for a flexible, ongoing organic dialogue with students. Flexibility demands a "high degree of control", or independent self-reliance on behalf of the students, which in turn leads to greater learning (Kanuka, Collett, and Caswell 2002:166). If it is the goal to encourage higher learning, then flexibility within online courses should be pursued. One example of promoting flexibility is limiting the formal guidelines of the discussion board in order to encourage emergent interaction. Kanuka, Collett, and Caswell's (2002) findings appear to have moderate validity in terms of the initial transition to teaching online, as they employed an in-depth interview design with purposively selected key informants (college professors who are new to teaching online).

Computer-mediated communication, then, appears to be of paramount importance in the online classroom. In order to understand $\mathrm{CMC}$, some of the practical applications of these advantages and disadvantages are in need of elaboration.

\section{The Computer-Mediated Student}

Online learning is personalizable in the sense that a student may "attend" course at any time and place of his or her choosing, which means that the learning process occurs at different times and places for different students. Students engage in both selfstudy and asynchronous interaction with teachers and other students via networked 
computers (Andrews \& Haythornthwaite 2007:30). Jaffe (1997) argues that allowing students to respond at their own pace on an asynchronous discussion board produces more thoughtful discussion than would be possible in a F2F classroom because of the added opportunity in which to reflect before transmitting a response. Others argue that non-moderated asynchronous discussions - those in which the instructor evaluates students' posts without responding to or guiding discussion - are "value-laden and, for some, potentially intimidating," (Andrews and Haythornthwaite 2007:4). This is because non-moderated asynchronous discussion is fundamentally different from the moderated and synchronous classroom environment to which today's student is accustomed. And, because online instructors often lack the resources to respond to students' posts, online discussion boards are often non-moderated. Thus, the online student faces a learning curve that requires cognizance of the instructor.

\section{Selection Bias and Self-Regulation}

Driscoll et al. (2012) conducted a quasi-experimental study to evaluate student performance and satisfaction across F2F and online courses. Researchers gathered survey data from 368 students enrolled in three online and three F2F sections of the same course taught by the same teacher at the same university. When controlling for GPA, the researchers found that there was no significant difference in student satisfaction or outcomes when comparing the two forms of course delivery. Further, both mediums adequately met "students' wishes for an interactive learning environment," (or the wish to work with other students and interact with the instructor). This latter point speaks to the 
teaching practices employed because "interaction, clear organization and structure, and a focus on content over delivery method," were used (Driscoll et al. 2012, 318). Thus, online students are satisfied with a moderately high level of interaction in online courses. Driscoll et al. (2012) argue that the variation in outcomes and levels of satisfaction across F2F and online courses has to do - in part - with a selection effect on behalf of the students. By connecting student grade point averages to survey responses, researchers were able to isolate lower-performing students from higher-performing ones. Results indicate that students in the online versions of the course had lower overall GPA's, and conversely students in the F2F version of the course have a relatively higher GPA (Driscoll et al. 2012); this suggests a selection bias in which lower-performing students seek out online courses, and higher-performing students seek out F2F courses. Because of the quasi-experimental methodology, Driscoll et al.'s (2012) findings are convincing. Researchers controlled for several variables; the same instructor taught an in-person section and an online section of the same course at the same time over three consecutive terms. Across all three terms, the selection bias outlined above was present.

It seems that students who have a preference for online learning perform worse in general than those who prefer F2F courses (Driscoll et al. 2012; Olson 2002). This has the effect of leading "stronger and more committed students to F2F sections...while simultaneously driving weaker, less dedicated students to the online sections, where they think they will encounter a reduced work load and lower expectations," (Driscoll et al. 2012, 324). In addition to being lower-performing overall, the students in the online 
section of this study were older, had more experience with online courses, were further along in school, were taking fewer courses overall, and were working several hours per week outside of academia (Driscoll et al. 2012); in this way, Driscoll et al.'s population is similar to the students attending the college in the present study. The average age of a Portland State student is 28 , and many are also working part- or full-time (Portland State Fact Sheet). This leads this researcher to believe a selection effect may be in play here as well. If it is the case that online courses attract a specific type of student, then teaching online may be a different experience than the one instructors are accustomed to in F2F courses. However, with the consideration of the selection effect as outlined here, this research "supports arguments that there is no inherent deficiency in the effectiveness of the online classroom," so long as certain teaching methods (such as emphasizing interaction, organization, and content) are employed (Driscoll et al. 2012, 325). However, because students decide when, where, and how to participate in course, teaching strategies can only go so far. Students must be able to make smart decisions about their learning.

The ability for an online student to self-regulate efficiently is crucial to successful learning outcomes. Online courses are unique because students have more choices to make such as when to "attend", when to discuss, and when to work on assignments. This presents a dilemma, as "the influence of self-regulation on academic success has been demonstrated repeatedly...[and] learner self-regulation can be more critical to academic success in online courses [compared to F2F courses]," (Williams and Hellman 2004, 72- 
73). Williams and Hellman (2004) conducted a quantitative analysis comparing the selfregulation skills of first- and second-generation college students. They note that selfregulation skills "are acquired through social sources such as parents and teachers as well as through instructional activities...[and] that self-regulation [is] significantly correlated with grade point average," (Williams and Hellman 2004, 72-73). Consequently, some students - and especially those who lack self-regulation skills - face significant hurdles in the online classroom and are likely more suited for F2F learning. While the literature lacks a solution for this problem, it seems with proper resources - such as teaching assistants, sufficient time, and appropriate incentive - online instructors can address the needs of each individual student.

Similarly, Moore (1972) suggests that distance learning cultivates and - to a certain extent - demands student autonomy. Autonomy can be thought of as the "captaincy of self" (Moore 1972:80), or the ability to be a self-regulating learner; autonomous learners do not require high levels of structure or dialogue from the teacher. Instead, autonomous learners fare better if they are given license to work independently, thus making the virtual classroom more suited to autonomous learning styles. Further, Moore theorizes that autonomy and distance are the "twin foundations" of individual learning (1972:84). He uses the term "transactional distance" to explain the studentteacher relationship. In essence, the theory of transactional distance refers to the "distance" between teacher and learner; some students need significant structure and frequent teacher dialogue (low transactional distance), whereas other, more autonomous 
students need very little structure and often are capable of learning without teacher dialogue (high transactional distance) (Moore 1972:84). Autonomous learners are able to conduct the learning process independently and successfully while being very "far away" from teachers (Moore 1972:82). Moore (1972) argues autonomous learners are better suited to distance learning because this kind of learner often has difficulty dealing with the synchronous, highly structured, and guided nature of traditional courses. However, Driscoll et al. (2012) find that online courses attract lower performing students who tend to need a higher level of structure and guidance, or what Moore would explain as low transactional distance; this kind of relationship, Moore explains, is difficult to establish in an online environment. Thus, online teachers may find it difficult to tailor the learning experience for the needs of each individual student. However, if instructors can find a way to evaluate the level of independence of each student, the challenge of selfregulation can be resolved.

\section{Two Rooms in the Same House}

Regardless of the disagreement among scholars, it is clear that online instructors need to change the way they teach and facilitate discussion online. As online instructors begin to incorporate asynchronous computer-mediated learning into their pedagogy, many challenges of teaching online are eliminated. Namely, as online instructors adapt to teaching online, they begin to see some unique advantages of online discussion. Despite the different tasks associated with teaching online and teaching in-person, research indicates that excellent face-to-face teachers make excellent "virtual" teachers, or that 
good teachers are successful regardless of the medium used for delivery (Kanuka, Collett, and Caswell 2002). Baglione and Nastanski (2007) gathered survey data from 303 online teachers at a private university in their quantitative study of online learning. The researchers only surveyed those who had taught both online and F2F courses, those who they considered "experienced faculty," (Baglione and Nastanski 2007, 143). Researchers found that only 21 percent of respondents prefer a F2F classroom over an online format, with the remaining 79 percent reporting that they either like both teaching formats equally (50 percent) or they prefer online courses (29 percent) (Baglione and Nastanski 2007, 147). Baglione and Natanski (2007) argue that online discussions facilitate more extensive discussion "because of research and reflective time, physical anonymity, and equitable distribution [of discussion]," (Baglione and Nastanski 2007, 148-149). Thus, there is an expectation that every student in an online course - not just the vocal minority of students in a F2F course -critically engage in every question posed. For these reasons, subjects reported a preference for online discussions over in-person ones.

Teaching online entails different responsibilities than teaching in-person. Baglione and Nastanski (2007) note that online teachers act as "gate keepers of learning" (140) rather than executing the traditional role of expert information delivery and inperson demonstration of content. Thus, some instructors perceive online teaching as a qualitatively different occupation because of the departure from the pedagogical strategies required for the performance of F2F teaching. It may be, then, that teaching 
online and teaching in-person occupy two different rooms, even if they are in the same house.

\section{Learning to Accept Technology}

How teachers perceive the usefulness and ease of use of technology will impact how they go about teaching online. Gibson, Harris, and Colaric (2008) measure acceptance of technology-based teaching. By using Davis' (1989) Technology Acceptance Model (TAM), they survey 110 individuals teaching online at a university in order to explain how they came to accept teaching with technology. Acceptance of technology is problematic for any subsection of society, as the "implementation of new technology is...characterized by fear of the unknown, concern over organizational changes and their implications, and criticism from many constituents," (Gibson et al. 2008, 355). In essence, TAM suggests that teachers fear technology both for legitimate personal reasons, and because their peers are critical of the new way of teaching. Results of Gibson et al.'s study (2008) show that professors' perception of the usefulness of teaching technology significantly influence their acceptance of it, because they "tend to be pragmatic in their acceptance of technology and place more emphasis on the compatibility of the technology with their duties," (358). These data do not suggest, however, that perceived ease of use had much of an impact on professor acceptance of teaching technology. Thus, initial perceptions held by professors and their peers of the usefulness of teaching technology may predict whether or not they come to accept the technology as useful, and consequently impacts the overall experience of teaching online. 
Weimer argues that "If faculty think their efforts in the classroom are not being supported, that affects their motivation and commitment," (2010:180). This challenge of committing to the online medium of instruction, it seems, can be overcome with the proper support from one's professional peers.

Negative evaluations of online learning are often of good intent, but ill-informed. From both a student and teacher perspective, the online classroom has some built-in disadvantages, but some of these disadvantages are better conceptualized as challenges because they can be reduced or eliminated. In order to teach effectively, online instructors should have the means (e.g. teaching assistants) to evaluate the needs of each individual student (Moore 1972), be sensitive to the fact that abstract concepts are more difficult to learn in an online course (Faux and Black-Hughes 2000; Clark-Ibanez and Scott 2008), understand that teaching online is labor-intensive, especially when discussion boards are used (Conceicao 2006), be actively engaged in the discussion board (Andrews and Haythornthwaite 2007), accept the fact that teaching online is facilitation rather than instruction (Baglione and Nastanski 2007), avoid the deposit model of instruction (Norton and Hathaway 2008), achieve high quality learning outcomes by facilitating inter-learner discussion (Clark-Ibanez and Scott 2008), feel supported by their professional peers in their teaching pursuits (Weimer 2010), promote engagement through discussion by breaking down a larger online course into small and permanent discussion groups (Cacciamani et al. 2012), and organize the course schedule before the course begins and in a way that is clear and easy to understand (Driscoll et al. 2012). 
Following such strategies minimizes the disadvantages of online learning and maximizes its advantages over F2F learning. For online instructors to engage in these effective techniques, they must be 1) aware of the most effective techniques and 2) be committed enough to online learning to pursue such strategies. For 1) and 2) to occur, online instructors must possess a salient online teaching identity and sufficient commitment to the medium. Mead's (1934) conception of the self and Stryker and Serpe's (1982) explanation of commitment, identity salience, and role performance are useful theoretical frameworks for putting teaching online into perspective.

\section{Symbolic Interaction}

In-person discussion and the subsequent perception of self and others is a central focus of this research. G.H. Mead's (1934) analysis of self is fundamental to the contemporary understanding of symbolic interactionism. Mead explained the self on a level that can be empirically, and not philosophically, adjudicated. This is based on the social behaviorist assertion that there is an intricate thought process associated with the stimulus-response model. His formulation attributes to human behavior an inherent reflexivity; in other words, individuals reshape their behavior in order to gain approval and acceptance from others, themselves, and the community. Mead's interpretation of the self in Mind, Self, and Society (1934) is rooted in the reformulation of the simplistic stimulus-response behavioral model proposed by psychological behaviorists. While the stimulus-response model outlines an important element of behavior, it disregards the fact that the human mind is reflexive and capable of thought preceding the emission of a 
response to stimulus. The whole is prior to its individual elements, and in this way, the self is discovered through others based on organized responses from social agents within a particular community (Mead 1934:271). In the classroom environment, the academically-relevant self is emergent, and is discovered, developed, and reinforced through interaction with others. Students react to information in the moment, and this helps teachers isolate the concepts that students are (or are not) comprehending.

Mead explains the higher mind as unique in its ability to react to a stimulus, isolate the important parts, manipulate the object, and take action based on the resulting interpretation. This is an organized response (Mead 1934:192). For example, in order to avoid sickness the human mind will examine a wild berry and consider whether or not it has threatening poisonous properties, while the lower animal mind lacks this ability, and gets by on trial and error. Thus, the human mind is based on reflexive reasoning which allows interpretation to precede response.

It is precisely this process of reflexivity and isolation of "important" stimuli that Kanuka, Collett, and Caswell (2002) argue is transformed in the online classroom. Until the rise of ubiquitous communication technology, human response was thought of as interpretation guided by reflexive logic, a process which is heavily influenced by the face-to-face emergence of the generalized other, which in this instance would be the students to whom the teacher is delivering pedagogy. The organized response of students-to-teacher and students-to-students has indeed been impacted by - or is transformed within - virtual space in unknown ways. I use Mead's framework to explore 
the ways in which the organized response process is transformed when teaching online as compared to teaching face-to-face, particularly the ways in which isolating the "important parts" - that is, observing student response to stimuli when you cannot physically see them - becomes a foreign endeavor.

An understanding of language and it's place in in-person dialogue (online and offline) is key to understanding the classroom environment. Individuals interact through a conversation of gestures (Mead 1934:155). Language allows this conversation to become meaningful (Mead 1934:166), when the response aroused in the person expressing the gesture roughly matches the response meant to be drawn out from the individual to whom the gesture is addressed. Simply, if two individuals share the meaning of a gesture or symbol, then it is significant. In this way, mind emerges through communication, and not the other way around; indeed, language makes mind possible. Face-to-face language, which can be heard as it is being emitted, is unique in its ability to be altered, so to speak, "on the fly". Language allows similar lived experiences to be shared. If someone says the word "dog", most people will create a similar mental image. If someone yells "fire!" most people will run for the nearest exit. For Mead, language satisfies the human need to engage ourselves and others in a shared mental process (1934:172). Mead's analysis of language implies that the social process comes before the mental process; significant symbols must exist for the mind to exist. Consequently the community has a great impact on the creation and recreation of the mind. The way in which teachers conduct course online is different than in-person, because online course happens asynchronously; 
students cannot rely on a spontaneous and emergent (face-to-face) discussion in order to draw out information because online interaction happens at different times and in different places. Thus, online students have to be self-reliant and willing to investigate problems on their own. Similarly, teachers must also cope with the asynchronous nature of online interaction, and must address student problems individually, rather than as a group. Mead's discussion presents theoretical support for why online teaching may be qualitatively different than face-to-face teaching because the social process - and subsequent mental process - is not the same in both teaching mediums.

Mead argues that an individual must belong to a community and be directed by the organized response of the generalized other in order to have a self. Burke and Stets (2000) reach similar conclusions on the complete self, and argue that "stronger ties to others through an identity lead to a more salient identity" (230). That is to say that belonging to a community creates and reinforces a shared identity, which becomes progressively more stable over time; this can be observed in a face-to-face classroom, for example, as the teacher and students in a particular classroom community will grow more comfortable with themselves and others, leading to more relaxed interaction.

The online classroom, then, provides teachers with a different teaching experience because their relationship (or the way they relate) to students is transformed. This has to do with the differing elements of self. Within the self, two discrete parts, the "I" and the "Me" exist (Mead 1934:229); the two concepts are related, they interact, yet they are different constructs. The separation of the "I" and the "Me" gets at the fundamental 
elements of self, in which there is a distinction between conformity (structure) and individuality (agency). The "I" is the immediate response of the self to others, or to stimulus (Mead 1934:229). It is the unpredictability of a situation caused by the creative and subconscious elements of self. Indeed, it is a source of "novelty and creativeness" present in all social individuals, and it is something that emerges in face-to-face interaction (Mead 1934:xxiv). If it were not for the "I", all individuals would be very similar. The "Me", on the other hand, refers to the adoption of the generalized other, or of stability (Mead 1934:232). As opposed to the unpredictable and unconscious nature of the "I", the "Me" is the conscious understanding of community expectations. It is societal control that maintains stability among individuals and, by extension, the community. Online learning may neutralize the spontaneous and emergent ("I") behavior because actors have time to reflect on their interaction prior to transmitting anything to others. The medium of transmission is fundamentally different because the spontaneous elements of self are reduced significantly (MacDougall 2005), or what can be thought of as the "I". In this way, online teachers are presented with a different kind of student, perhaps requiring them to be a different kind of teacher. The roles individuals occupy are particularly relevant to this discussion of online learning.

\section{Identity Theory}

Symbolic interaction, identity salience, commitment, and role performance are intimately related concepts. Stryker and Serpe (1982) explain that identity theory evolved from symbolic interactionism, but is a more focused portrayal of social interaction. 
Individuals acting within a particular social structure assign names to one another based on the recognition of each other as occupants of roles; and, because identity is reflexive, individuals also apply occupational names to themselves. Occupations are associated with a set of expectations that people assign to themselves and others and use to perform roles. Individuals can possess any number of role identities simultaneously (such as brother, father, teacher, Christian, and so forth). Roles are sometimes played according to a presupposed set of expectations. Teaching in-person can be thought of as playing a role because the training needed to become a teacher involves the instruction and modeling of such a role. On the other hand, roles are also made. Teaching online can be thought of, in some cases, as making a role because there is no clearly established pedagogy (Levine and Sun 2002) or strategy which would inform role performance expectations in that setting. The extent to which roles are made rather than played depends on the "openness" of a social structure; some structures allow more novelty in roles than others (Stryker and Serpe 1982). The meaning of social structures is found in how choices are made possible or constrained, such as "who is brought into contact, what possible role relationships can emerge, [and] what resources can be used in these relationships," (Stryker and Serpe 1982, 208). I propose that a university structure is fairly open if it allows faculty to selfdetermine expectations for teaching online (role making), which may involve choosing to deviate from the expectations of teaching in-person (from role-playing to role-making).

The relationship between identity, identity salience, and commitment is an important one to describe if role performance is to be explained. Identity is nearly 
synonymous with the idea of role; in fact, some have used the term "role-identity" as opposed to just role or identity (Burke 1980; McCall and Simmons 1978). This is because the occupation of a role and the internalization of expectations influences behavior and subsequent reflexive analysis of the self. The degree of importance of an identity ("identity salience") depends on its location in one's personal hierarchy of roles; the salience of one identity (such as "professor") presupposes the relative transience of other identities (such as "brother"). Furthermore, one's personal commitment to an identity - that is, how much time and energy an individual invests in a role - depends on the extent to which significant social relationships are based on a particular identity. Commitment is often influenced by the salience of the relevant identity, but not as a rule; one can possess a strong role-identity without feeling the need to make a significant time investment in that role, and vice-a-versa. In other words, a professor's identity is significant because the connections to students that a professor might make are premised on his or her identity as a professor and this in turn can elevate commitment. And, because there is a shared understanding of the expectations of the professor role, committed professors will perform that role in a predictable and consistent manner. Further, if an instructor feels his or her in-person teaching role and ability to lead F2F discussion is particularly salient, developing a salient online instructor identity will be all the more difficult, and commitment level will suffer. Thus, role commitment is influenced by “...the number of others to whom one relates by occupancy of a given 
position, the importance to one of those others, [and] the multiplexity of linkages..." (Stryker and Serpe 1982, 207).

The level of commitment one has to a role influences how role-performance plays out. Stryker and Serpe (1982) adjudicated these theoretical assertions empirically, and found that "commitment and identity salience account for much of the variance in role performance," (213). Extrapolating this to an online teacher suggests that his or her role performance - operationalized as the pedagogical choices made and the subsequent satisfaction with online teaching - is determined by the level of commitment - how much time he or she invests in the occupation - and the salience of the online teacher role to that individual - how important the occupation is to the instructor, which is premised in part by the quantity and quality of interactions an online instructor has with others that are premised on his or her role as an online instructor. Further, if it is the case that identity salience is partially based on role-based interactions with others, faculty may place lesser salience on their online instructor identity if their interactions with other faculty and students are lessened in quantity or perceived quality. 


\section{CHAPTER 3: METHODOLOGY}

In this chapter, I discuss how I collected and analyzed interviews with online social science instructors at Portland State University. I outline Kanuka, Collett, and Creswell's (2002) work on teaching online that guided the construction of interview questions and coding sheet categories, though both the interview guide and coding sheet evolved during data collection. Additionally, I discuss methods for qualitative data analysis, as shaped by Strauss and Corbin (1998). Finally, I discuss subject and content recruitment, and methodology.

\section{Constructivist Phenomenology}

Constructivists argue that there is no way for researchers to objectively understand the lived experience of another, and that this assumption should lead researchers to avoid imposing personal interpretations in order to allow subjects to make and assign meaning for themselves (Marshall and Rossman 2011). This research is grounded in constructivist phenomenological inquiry, and therefore allows the subjects to dictate which concepts are the most important. Accordingly, and bearing in mind the goal

of theory generation, this project relies upon the constructivist paradigm. This perspective asserts that an individual understands the world from his or her own subjective experience; social agents assign meaning to things in the social world, and interpret this meaning subjectively. This research is informed by the constructivist perspective developed by scholars who examine subjectivity, identity, interaction, and lived 
experience, all of which are crucial to understanding the experiences of online professors. Furthermore, this research utilizes a grounded theory approach. This inductive approach does not interpret data through the lens of a particular theory as could be observed in deductive, theory-testing research methods. Grounded theory is an approach to data collection and analysis that is systematic but flexible; the goal of the grounded theory methodology is to supplement existing theories or create new ones which are "grounded" in the data (Charmaz 2006).

\section{Why Qualitative?}

In order to address my research questions, I conducted semi-structured, formal interviews with online social science instructors at Portland State University. An in-depth interview design is appropriate for this study because, in adhering to constructivist assumptions, the best way to understand a lived experience is to allow respondents to provide detailed descriptions of their understandings in their own words (Marshall and Rossman 2011). Semi-structured in-depth interviews allowed respondents to explain how they design instruction, deliver information, facilitate discussion, and adapt techniques-as well as how these components of instruction differ or persist across face-to-face and online formats. I wanted to examine what teaching online means to university professors; thoughts, feelings, beliefs, values, and assumptions explain perceptions and behaviors, and semi-structured interviews capture these data. Quantitative methods alone would not reveal the process by which people form their pedagogy and the environmental conditions which inform it. Furthermore, Major (2010) explains that quantitative research 
exploring teaching online has elucidated faculty perceptions of benefits and drawbacks of the medium, but without getting at the deeper meanings of these perceptions. On the other hand, qualitative methods allow me to transcend questions of "what?" or "how many?" and instead explain the core inner-workings of social phenomena: the "why?" (Miles and Huberman 1994:10). Because the goal was to understand a potentially burgeoning issue for university instructors, a survey instrument was inappropriate. The survey instrument would have required me to foresee answers and form them into simple categories, which was not possible due to the lack of research in this area. Thus, qualitative methodology was essential to the success of this research.

Subjects were instructed to use their own words to explain what characterizes successful information delivery and high-quality classroom discussion, and how they evaluate students in both mediums. Some aspects of grounded theory, as outlined by Charmaz (2006), were used. Data analysis occurred parallel to data collection, and interview questions were formed and reformed based off initial findings. Initially, I asked: “(1) How do PSU social science professors experience online pedagogy? (2) How do PSU social science professors evaluate their ability to deliver information and facilitate classroom discussion in an online setting as compared to a face-to-face setting? (3) Does teaching online require similar skills as teaching face-to-face? (4) Does teaching online influence how PSU social science professors construct meaning about themselves as educators?" After two pilot interviews, it became clear that research questions two and three were irrelevant; it was immediately evident that (2) evaluation of students online is 
very similar to in-person, but that (3) new skills are required to carry out such a task. What is less evident is why some instructors are highly committed to the online medium, while others are not. Thus, my terminal research questions are: (1) How do PSU social science instructors perceive facilitating discussion in-person and online? (2) What is the process that determines the degree to which PSU social science instructors are committed to teaching online? (3) Does teaching online influence the way in which PSU social science instructors construct meaning about themselves and their role in higher education?

The review of literature also continued throughout the data gathering process, which caused my research questions to evolve over the duration of the study. Each stage of the research enabled data triangulation in order to ensure a valid and thorough understanding of how online social science instructors experience teaching online.

\section{Site Selection}

The study took place at Oregon's most highly attended university: Portland State University (PSU). This institution is an appropriate site for this study because the population of professors includes individuals who have taught both online courses as well as in-person courses. PSU reports that by 2014, the university will have improved and expanded online learning, with upwards of $20 \%$ of all course offerings taking place in the online medium. Specifically, administration intends to "establish and communicate incentive structure for faculty participation...establish course/program migration 
plan...[and] identify location for long-term home for Center of Online learning," (University Planning, PSU, 2011-2014:18). Clearly, and in congruence with the perceptions held by administrators in Allen and Seaman's (2009) study, PSU administration places much stock in the potential of online learning. PSU professors themselves are appropriate subjects for this study because - as online enrollment continues to grow at this university- their occupation may be subject to fundamental changes.

\section{Sample Selection}

The nature of the research questions demanded a non-random quota selection method. Criteria for inclusion into my sample included several variables. In order to address the lived experience of both teaching face-to-face and teaching online at PSU, the selection process sampled for individuals who have taught the same course face-to-face and then online. By controlling for the same course taught by the same teacher, spurious data relating to other aspects of teaching were minimized. This one-to-one comparison of the same instructor teaching the same course across the two mediums would not be possible with students, and is a methodological strength of this study. Additionally, All respondents are PSU professors of social sciences. Research has indicated that social science disciplines may lend themselves to face-to-face styles of teaching (Faux and Black-Hughes 2000) and existing qualitative research on this topic has not taken specific disciplines into account (Major 2010). As such, the scope of this research will focus on social science educators at PSU. By holding all other disciplines constant, the findings of 
this research are transferable to online social science instructors at other urban universities that are similar to PSU.

Other criteria were also taken into consideration. Because Kanuka, Collett, and Creswell (2002) find that grievances with the technical aspects of teaching online dissipate after a few years, respondents were required to have been teaching online for at least four years. Additionally, all respondents were required to have a Master's degree or higher with at least four years of experience teaching in-person at the university level. This ensured that the interview data would derive from those with a familiarity with teaching in the traditional face-to-face format. Similarly, respondents were asked to only discuss an online course at the "200" level - roughly, the level of second year college students - or higher in order to avoid gathering data on the trappings of teaching online when the students are new to the technology. So long as the course was "200" or higher, it was assumed that the students had some time to get to know the requisite software such as Desire2Learn (D2L) in the case of PSU.

I used PSU's online registrar to locate possible participants. Of the population of PSU professors, 35 social science instructors were found who had taught in-person and online. This sample was contacted via e-mail with the screening survey which established if the respondent 1) possessed at least a Master's degree, 2) had taught in-person for at least four years, 3) had taught online for at least four years, and 4) had taught the same course in-person and then later online. Of those 35 contacted, 15 responded. Interviews were conducted in September through December of 2012. Interviews were conducted 
either face-to-face in my office at Portland State University or via Skype, a videoconferencing service. Interviews ranged from one to two and a half hours. An interview guide (see Appendix A) gave structure, while also leaving room for unintended responses and discussions in order to ensure the interpretive validity of my findings (Johnson 1997). The guide was founded on the review of literature (In particular, Kanuka, Collett and Creswell 2002). Data saturation was evident upon analyzing the eighth interview, and was apparent upon the tenth, which resulted in ten subjects $(\mathrm{N}=10)$ being used for this study (see Appendix B). All names have been changed to pseudonyms to maintain anonymity. This sample does present variation in gender (six females, four males), yet is homogenous in race as all respondents are reportedly white. While racial minorities were not intentionally excluded, it is convenient for theoretical considerations that this sample is only white; Stryker and Serpe (1982) note that their work on identity salience and commitment does not transfer well to racial minorities because racial identities intersect and supersede other ones. While demographically homogenous, this sample presents greater differences among educational background.

This sample represents a breadth of experience. Five respondents hold a Master's degree, four hold PhD's, and one holds a JD. The range of online teaching experience is from four to fourteen years, with an average of about seven years of experience. This balance of credentials and experience was intentional in order to accurately portray the diverse population being sampled; "...we can learn much from experienced online learning instructors, [but] we can also learn from the fresh perspectives of new online 
learning instructors..." (Kanuka, Collett, and Creswell 2002:166). Indeed, institutions of higher learning must be careful to be "continually reflective" and not only rely on strategies which worked in the past (Kanuka, Collett, and Creswell 2002:166). The present study appropriates attention to new as well as established online teachers in hopes of reflecting the overall category of social science professors who teach online at universities similar to PSU.

\section{Data Collection}

The interview questions evolved as each interview was conducted and as new literature emerged. The first interviews were shorter and did not have as many probes and discussions as the later interviews. However, as each interview progressed, the interview guide was slowly molded into a more valid and reliable instrument. After this first round of interviews, I re-evaluated my interview guide by adding more probes and additional areas of discussion, guided by my initial interviews and a closer examination of the literature. For example, when it became clear that teaching online is an overall transformative experience, I added the probe, "In what ways - if any - has teaching online changed the way you think about your teaching methods? In what ways - if any has teaching online changed the way you build relationships with students?" Interviews began and ended within a four-month window. The 10 interviews obtained did have significant recurring themes and the findings are sociologically important and are grounds for further research. 
I carried out verbatim transcriptions of the recorded interviews to aid in a close analysis of the responses and to enable analytical coding. Respondents explained how they know information delivery has been successful, what makes a "good" classroom discussion, and how embodied and disembodied space is connected to these processes. This collection method is also congruent with the assumptions of a phenomenological grounded theory approach, in which emerging ideas guide data collection, synthesis, and analysis (Charmez 2006).

\section{Data Reduction}

The interview transcripts were qualitatively coded. By building a codebook with an inductive approach, the most pertinent themes and code categories emerged. Patterns within the codes were identified, and the subsequent themes are the framework for the codebook. Performing this qualitative analysis enabled pattern detection among themes as well as interpretation of data. I conducted open-coding (Strauss and Corbin 1998) on the interview transcripts. This included reading the data, highlighting salient quotes, and familiarizing myself with the similarities and differences among the different transcripts. I started to identify and note recurring ideas, concepts, and opinions. I then started to find commonalities amongst the transcripts and conducted axial coding ${ }^{1}$ (Charmaz 2006, Strauss \& Corbin 1998) in which I identified intersections and started to cluster categories. As key concepts started to emerge, I looked for commonalities and combined them into themes. Collapsing categories elicited major themes among the texts and

\footnotetext{
1 Axial coding "relates categories to subcategories, specifies the properties and dimensions of a category, and reassembles the data you have fractured during initial coding to give coherence to the merging analysis" (Charmaz 2006:60).
} 
interviews. Once I developed the dominant themes from each source, I examined all dominant themes across the various texts, stories, and interviews, looking for commonalities and divergences

\section{Data Analysis}

Previous research helped to clarify initial concepts, suggest thematic codes, and guide the grounded codebook, which became more focused as data was collected (Marshall and Rossman 2011). The interviews were transcribed in a "rolling" method: transcribing interviews as they are completed and performing analysis as data are still being collected. Doing so helped refine the data collection instrument. Analysis was an on-going process - a process which necessitates constant comparison of interviews with one another. Using memos kept data analysis organized, and allowed me to reflect on the continuous thematic threads throughout the data (Charmaz 2006). Doing so also provided a better understanding of how participants develop and assign meaning to their teaching choices. 


\section{CHAPTER 4: FINDINGS - Adapting to the Asynchronous Classroom}

In this chapter, I will first describe the in-person pedagogies pursued by respondents, followed by the ways (if any) in which they changed their methods when they began teaching online. This section addresses the first research question: How do PSU social science instructors perceive classroom instruction and discussion in-person and online? A substantial segment of the interview was dedicated to uncovering the inperson pedagogies of these respondents in order to identify similarities. Analysis revealed a key theme: Respondents explain that the text-based, any-time, any-place online classroom is qualitatively different than the in-person classroom. This means some of their responsibilities are different when teaching online as compared to in-person. Respondents indicated that while the skills necessary to teach in-person include the ability to create an interactive environment of collaborative exploration, quality online instruction primarily demands organizational discipline, including the routine moderation of the discussion board. Built in to this shift is the reduced centrality of the instructor to the learning process, which is difficult for some instructors to come to terms with. As a way of dealing with stymied control over the course, instructors expect their students to be proficiently independent, including the expectation that students find their own way of mastering the content. Discussion becomes more akin to routine essay assignments, and is quite different than a conversational, F2F discussion. Consequently, instructors must adapt their methods to the distinct characteristics of the online classroom, which requires the 
awareness of how to do things differently and the persistent commitment required to carry out such tasks. Further, ample resources lead to instructor success and commitment to the online medium. Resources include environmental factors such as peer support and practical resources such as financial incentive, access to teaching assistants, and the ability to maintain one's teaching style via the retention of at least one face-to-face course in addition to the online courses. Respondents also indicate that teaching online is a gradual process of adaptation that gets better over time, a process that requires trial-anderror.

The respondents in this study share many pedagogical similarities. All respondents use an asynchronous (as opposed to synchronous) online classroom. Further, all respondents employ a Socratic style, a pedagogy that emphasizes open dialogue interjected throughout the lecture. All respondents faced similar pedagogical challenges when transitioning to the online format, as the asynchronous online classroom simply does not facilitate a spontaneous teaching method such as the Socratic style. Each respondent experienced a process of transition that was unique but also followed a general pattern. In order to elucidate the ways in which the respondents alter their methods when teaching online, a brief discussion of their in-person methods is necessary. In the following section, I will discuss how instructors transmit content in-person as compared to online. 


\section{Transmitting and Learning Content In-Person}

When teaching in-person, respondents explain that the heart of teaching is creating an interactive environment in which the course collaboratively explores difficult concepts. The abstract concepts of the social sciences lend themselves to collaborative exercises, and respondents worked hard to foster interactivity in their in-person courses.

In the in-person format, instructors transmitted content via an interactive lecture, including discussion and small group work.

"Students would come to course and would be prepared with a discussion response... we would break into smaller groups to tackle particular questions and talk about those and bring them back into the larger group... students work together. They would do small group projects where they would develop and present particular lessons. I rely very heavily on discussion...in all my courses there is a very interactive element even when I spend perhaps a couple times a week lecturing, I still encourage interaction questions and comments during my lecture." - Jacky

Jacky's description of her lecture style is exemplary of the respondents in this study.

Some respondents rely more on lecture than others do, but all are emphatic about the importance of interaction with and between students.

"In the classroom... we had one long book ... and the assignment was every week they read two chapters, and then during course we took turns reading [a third chapter]. It slowed things down, but it gave them a chance to really take in the information ... I teach from the framework of let's explore information together, let's create knowledge together." - Maureen

Respondents explain that learning happens collaboratively. By encouraging "cross-talk", instructors enhance learning outcomes.

"My belief was I was there not only to deliver a lecture of bullet points that I had outlined, and to cover the material, but also to hopefully say some things that would be controversial or interesting, and people would say, oh wait a minute I 
don't understand that, or I don't like that. So interaction was a big thing...the more we talk sideways, the better. If you have a live course, one of the things that is

nice about that is getting cross-talk going, and having surprise things come up. It's part of the reason why I still prefer in-person teaching, because even as an instructor, the level of spontaneity is much higher." - Matt

Respondents stress that encouraging interaction is key. If students do not understand something, they can inquire with other students or the instructor on the spot. In this way, a "live" course helps instructors provide the students with a high level of engagement with the material and avoid confusion.

"[In-person] brainstorming helps to say we all read the chapter, so what were the three most important things for you? And someone will raise their hand, and we get them up, and then we start talking about them. And it wasn't just me talking about them, I try to illicit students to say, is there anything else about this? So there seems to be more engagement." - Nicky

\section{Transmitting and Learning Content Online}

\section{Disadvantages}

Respondents explained that the transition to teaching online was a process characterized by trial and error. Many of them referred to it as a gradual transformation during which they came to understand the skills they had painstakingly developed over years of teaching face-to-face suddenly became far less valuable when they transitioned to the online classroom. The key hurdle was computer-mediated communication, as indicated by difficulty with text-based, any-time, any-place communication; in turn, they were faced with the challenge of creating student engagement with the material in the new medium. The loss of visual cues and spontaneity that is inherent in F2F interaction was an issue for many. This shift in the nature of interaction is exacerbated by the fact 
that respondents' online courses have many more students than their in-person ones.

Respondents dealt with this in varying ways, but all felt their skills were less relevant to the online medium. This confirms Conceicao's (2006) finding that online instructors feel restricted because of the loss of spontaneity.

"So there is something that is certainly lost. I'm very passionate about learning and teaching, and it's much easier to convey that in person... there is certainly something to be said about that face-to-face interaction, you know you're in the milieu, and I think especially, if you can create an environment where people are excited to be there, and excited to be learning, it's harder to do that fully online." - Doug

"It's challenging to design my courses and to balance out the text-heavy nature of my courses, but I don't know if that's going to change completely. I don't know if I'll have the ability or the time or whatever it is to do that.... I also think you can't rely on the old tools; you have to find new tools. Like I said, if I don't have facial cues, I have to find other ways to be sensitive to where students might be struggling, you know, how can I communicate better? All of these kinds of things that are integral to teaching well." - Jacky

"I do think in-person if someone seems bored, checked out, it's easier to engage them. If someone is not in course, you know, if it's a smaller course. So to that extent, I have better one-on-one interaction with all of the students in-person at this stage, but I suspect that will change as time goes on." - Darcy

Thus, in-person teaching skills lose relevancy in the online medium, and new strategies must be developed. An instructor's responsibilities are not the same in the online classroom as they are in the in-person classroom because the environment is different. Instruction is computer-mediated in the online classroom, and as a result, teaching and learning does not happen in the same place at the same time, as would be the case for in-person courses. This asynchronisity makes collaborative learning a challenge in the online format. Respondents emphasize collaborative learning, and have difficulty re-creating this in the text-based online classroom because some lack the 
awareness of how to do things differently. While there are ways to circumvent the textbased nature of the online classroom (E.g. posting video-recorded lectures online or video conferencing one-on-one with students via Skype or similar software), few respondents deviated from text-based communication. A few subjects (Brad and Naomi) occasionally record and post lecture videos, but they say that this is cumbersome and time consuming. They lack a practical way to break free of text-based teaching, and this is one fundamental difference between online and F2F teaching: everything is written rather than spoken, and discussion is read rather than heard. Brad likens online instruction to writing a textbook.

"The writing, you know, is just more labor intensive in how much you want to write...it's almost like writing a textbook about it." - Brad

Some respondents explained that the in-person format is much more casual, and students are more willing to be informal and spontaneous, which in turn helps clarify content. Furthermore, respondents explained that online students feel more pressure to be formal and precise in online discussions, rather than informal and explorative as in the face-to-face format. Matt finds informal dialogue as an important part of the learning process. Without it, he fears students may not seek help when they are confused.

"I feel students are always under a microscope in an online course, so that everything they do, for one thing it's written, so everybody can go look at it. And they fear [they] can be penalized if you ask a quote unquote dumb question, but in-person you can definitely get people to ask a dumb question, and dumb questions are usually the best questions...you don't want somebody raising their hand and say, I understand everything in this book, and on page 73 it says blah, blah, blah, and of course that means blah, blah, blah. I mean, that's not a good question. "What do you mean?" is often times a fantastic question." - Matt 
Many respondents grieve the loss of emergent interaction in the online classroom. Brad finds the online classroom as bereft of informal and organic social interaction, and alludes to his appreciation of it as an instructor.

"[The online course] doesn't have sort of that more personal side to it, or I haven't found a way to really capture that. Whereas in the in-person course... I can chat with them and I can have small talk. There typically isn't any small talk going on in the online environment, it's pretty much all business." - Brad

Jacky also feels that online discussions are lacking on some level. For her, what is missing is less tangible, but rather is something that is felt.

"When a discussion goes well, it is palpable. You can feel it, you can sense it, you can tell that students are engaged, and they're committed, they're there; they're present. You don't get that benefit to the same extent in the same way with an online discussion." - Jacky

Coppola, Hiltz, and Rotter (2002) would agree, as indicated by the finding that relationship-building tools that were used in F2F courses are lost in the online medium. In a few ways, then, the new environment has some built-in challenges that instructors must learn to cope with.

\section{Advantages}

However, there are some perceived advantages of the online discussion board. There is more accountability in an online discussion (for both students and instructor) because everything is formalized, written, and archived. Thus, despite the lack of explorative dialogue, some respondents feel the online discussion board is of higher quality than F2F discussion. The archived discussion enables instructor evaluation of each student with much greater efficacy than in-person. In a sense, online discussion 
allows the instructor to be omnipresent and hold each student accountable. This supports McShane (2004) who found that the archived permanence of the online discussion board bolsters the sense of responsibility that students and instructors feel towards an online course.

"Whether you use a chat room or a discussion board, there is a record of everything that is said, whereas when I'm in the classroom and I say get into groups and discuss this, and I walk around and try to monitor what they are talking about, but you don't have a record of what they said. You don't really know, you can't really give them individual feedback because you don't know everything that was said. You can't really evaluate their participation as well because you don't know what different people brought to it." - Karen

Another major advantage of the online discussion board as reported by

respondents is that the online discussion board is quite different from in-person

discussion. In fact, to call it "discussion" may be a misnomer; it is more accurate to think of online discussion as small, routine writing assignments. Like writing assignments, online discussion happens independently and asynchronously, which allows the student to reflect and revise a response before submitting. This is a major plus for Doug, as he feels it better serves the writing needs of students.

"One thing I did right off the bat in that [online course] was I also had them participate in discussions. And I have graded the discussions. And they haven't really been discussions, they've been more like, I now call them short essays slash critiques. They write a very short essay and then I ask them to critique each other's essays." -Doug

\section{Structuring Student Interaction: In-Person}

In addition to the difference between mediums in how instructors transmit content, there is also a difference between the two formats in how instructors must 
structure student interaction with the course content. In the physical classroom, students interacted with content independently, and then were able to apply what they learned through face-to-face interaction with their peers. Karen describes her in-person strategy when she says,

"[In-person] they read a couple chapters each week out of a standard textbook. We have weekly quizzes. We have a weekly discussion, where they have to post something original in response to my questions by Wednesday and respond to at least two other peoples' post between Thursday and Saturday. And then two exams and a final. I would usually only lecture for the first hour and have them do some kind of group activity for the second hour. They [interact with each other] a lot; I think it is partly my background, where I have a very strong belief that we learn a lot from our interactions with each other in addition to from the professor... I think was the most valuable, that discussion hour." - Karen Her F2F approach is an exemplar for respondents in this study. Generally

speaking, instructors organize their in-person courses around interactivity; students read material independently, they listen to a lecture from the instructor that models how to deal with the material, come together to discuss, and then are given routine assignments to reinforce their new knowledge. Forcing students to interact with one another via small groups is crucial to this process.

"I feel it is really good for the students to have that opportunity to work in small groups together, and then come back together. There are different learning styles that people have. Some are auditory, some are visual, some are kinetic where they need to kind of get up and move around, so I like to kind of incorporate as much as possible that into the course. So if I did just straight lecture, I don't care how interesting the topic may be, at some point people are going to get bored." Naomi

Naomi explains that when students interact with one another in a small group, students are provided with multiple ways to learn the information. This helps to keep students engaged and interested, and in turn strengthens learning outcomes. 
The F2F nature of the in-person format makes it easier for instructors to coach students on writing assignments. Jacky explains that being able to meet F2F with students is an important part of the writing process.

"I make written comments on their papers, and some students have told me that's been helpful... And I have had experiences in the past with many [F2F] students of walking them through their paper and talking in very specific ways about what needs improvement and what are some strategies they can use to strengthen their writing skills and things like that." - Jacky

\section{Structuring Student Interaction: Online}

Respondents noted that whereas F2F instructors present students with information in the lecture format, online instructors direct students to sources of information. In this way, students are interacting with information rather than interacting with other people. This means that students are reading about - rather than hearing and talking about course concepts. This is congruent with Major's (2010) finding that the online classroom supplants human contact with collecting information, a process she calls "informating".

To assess the impact of this is difficult; while technology diminishes "sensory- or expressive-based skills", informating is a skill that may be more relevant to the future professional lives of the students. Nicky describes how online learning is more independent and less collaborative than F2F learning.

"[I select] specific websites related to the topic of the week, and I ask them to go to this and directed them to certain topics or certain sections. They will read, and then [write a discussion post about] two things that they learned from reading the segment. And so, the students seem to really like that, as adult learners, if they get to go out and explore this website, and they come back and say this is what I learned, and it made me think about this or that." - Nicky 
"[The online and in-person courses] were totally different in design. [Online] they are more doing their own thing... I think they would like it more if we did live chats and discussions, but I'd have to have some help with that, or do different kinds of assignments." - Maureen

In response to the variance in how students interact with content and with others, respondents change their assignments online. As Naomi became cognizant of the textbased nature of online learning, she reduced her discussion board requirements. She feels it is unfair to require them to post frequently if they have to read course materials in addition to reading the course itself.

"I've kind of lessened some, not much, but a little bit fewer discussions and things like that, to give them time to focus on something else. Again, recognizing that they are reading everything, although at their convenience, but still they are reading everything, and that does make a difference, and plus they have the course work to read too." - Naomi

Jacky feels that this text-based environment and lack of interactivity makes coaching on writing particularly challenging; without a "live" course, she cannot model effective writing as easily. This is troublesome for her, as teaching writing is central to her discipline (as it is for many - if not all - social sciences).

"I feel in one important way I cannot help students as effectively with their writing. I just feel that without the ability to meet with students [in-person] I'm at a disadvantage, and they're at a disadvantage." - Jacky

In order to address the issue of teaching writing skills, instructors say they need to be immersed in the discussion board. Respondents explain that they feel they are at their best when they are actively engaged in the discussion board. Andrews and Haythornthwaite (2007) stress that it is crucial for an instructor to be engaged in a discussion board, even if it is labor-intensive. It is not content expertise that poses an 
issue for instructors. Rather, the labor that goes in to staying on top of the discussion board is what becomes a challenge. This requires time commitment levels above and beyond in-person instruction

"The skills part, content expertise is baseline given, but the other skills are, you really have to be on it. Our website says that we'll check [the discussion board] once a day. Bull. We check it probably 15 times a day. That part can be a little stressful." - Darcy

This is in part because of the larger course sizes; in the extreme example, Rob instructs an online class that allows up to 140 students to enroll. However, some have found a way to circumvent this labor. Many respondents broke down their large online course into several smaller, more manageable groups. Brad, Rob, Darcy, and Karen, for example, break down their online courses into smaller groups that are managed by the instructor and teaching assistants (a necessary resource for this strategy). This provides students with a consistent, knowable peer group with which they can develop rapport as they would in an in-person small group. This also helps students stay on task.

"I want them to work with other students. We do that even in the online. Online, we'll take 140 students, and we'll break them down into 10 small learning communities so the students see only 14 students in the course. Whereas the students in my course generally know, well they know something about each other. It's generally a good idea to develop some cooperative working skills. I think there's some real advantages when [the students] work with other people.... If they are working alone and get behind, it's not as easy to get them back on track online as it is in-person." - Rob

\section{Relinquishing Authority in the Online Classroom}

Most respondents note that the instructor is central to the learning process in a F2F course but not in the online format. While some respondents indicate relinquishing 
control in the F2F format - for instance, Maureen's emphasis on a "classroom of teachers" - it is particularly prevalent in the online format. Smith et al. (2002) reached similar conclusions when they explained that the online classroom changes the faculty role from leader of learning to facilitator of learning. Consequently, transitioning to the online format demands that the instructor relinquish control of a course. In an in-person course, the instructor decides when and how course is executed. In the online format, the students decide when to "attend" course and when to create discussion posts or respond to their peers' posts. An in-person discussion also tends to be heavily mediated by the instructor, the respondents explain. Some respondents are heavily invested in the notion that the instructor is the leader of learning.

"I'll even let you guys debate with each other, but I'm the master of ceremonies so you have to shut up when I tell you to shut up. Online, it's totally different". Matt

Doug provides some insight into why instructors feel this way. He says that it is only logical that the instructor guide the learning process because they possess the knowledge and experience that the students would like to have, but do not possess.

"I think the great majority of a course should be more focused and that the instructor needs to be involved and giving feedback, because you're trying to teach people to do something that they're not as good at as they would like to be or they would need to be. And that's why we're there is to help them improve, so I don't see how we can do that unless we're engaged and giving them feedback." Doug

Some respondents directly acknowledge the need to relinquish authority, while others do not. Rob is one such respondent who understands that the power dynamics are different in an online course, and that this can be particularly challenging. 
"The ability to share authority, to share control for the course can be challenging, because in the classroom you are clearly running the show. And many people are very, very comfortable with that....and I don't think that's a really effective approach in an online environment." - Rob

Despite the challenge of relinquishing central authority, many respondents dealt

with it quite successfully. For Karen, the restructuring of power in her online courses was not problematic but rather was advantageous. By surrendering central leadership of the learning process, Karen places more responsibility on the students. In turn, students develop initiative that they will need when they start their careers in the "real world".

"I feel much more like a facilitator of learning than a teacher. Cause a teacher always meant to me before that, you know, I knew [my discipline] inside and out, and let me teach you what I know, and [teaching online] just isn't about that at all...this is, let me help you build on your skills, let me help you find the tools, find the resources that you need to, and steer you towards the connections you need to make to accomplish this learning." - Karen

\section{Conclusion}

Respondents in this study have very similar in-person teaching strategies, and subsequently deal with very similar pedagogical challenges. According to these instructors, it is true that abstract concepts are more difficult to read and write about online (Faux and Black-Hughes 2000). This requires instructors to put in great effort to teach these concepts, in addition to the inherently laborious nature of the text-based classroom (Conceicao 2006). However, these respondents do not attempt to evaluate students independently, as Moore (1972) suggests. Rather, they avoid the feeling that they are responsible for each individual student by expecting their students to be highly independent and capable of self-regulation. In other words, instructors work hard to 
moderate the discussion board, but if a student is not autonomous enough to keep pace with the readings and make an effort to post discussions, instructors are powerless. However, and perhaps unwittingly, many respondents follow Cacciamani et al.'s (2012) advice to use small groups even in an online course. If teaching assistants are accessible, these respondents manage their moderating duties by breaking up their large online course into small groups and assigning one group per assistant. Doing this means the instructor relinquishes some of his or her authority, but results in the benefit of students interacting with one another more often. This leads to higher levels of learning by enhancing the frequency and (perhaps) the quality of inter-learner interaction in an online discussion (Clark-Ibanez and Scott 2008). 


\section{CHAPTER 5: FINDINGS - Commitment and Changes in Meaning}

In this chapter, I will explain the respondents' success or lack of success making the transition to the online format. Specifically, I will address research questions two and three: What factors influence the degree to which PSU social science instructors are committed to teaching online? Does teaching online influence the way in which PSU social science instructors construct meaning about themselves and their role in higher education? One main theme and a few subthemes emerged through coding and analysis. There are some necessary conditions (namely, peer support and access to teaching assistants) required for instructors to successfully adapt to the online medium. If an instructor is able to adapt to the online classroom, meaning structures change. Adapted instructors tend to rethink what is possible and shift their understanding of what students should gain from a college education (e.g. from mastery of content to mastery of selfregulation and academic independence). Adapted instructors imagine new ways to teach online and in-person (if they teach F2F). They also begin to truly embrace teaching online, whether that be for personal or pedagogical reasons. Over time, instructors begin to value their interactions with online students and the quality and quantity of interactions increases. This in turn leads to heightened salience of online teaching identity and subsequent time invested. However, it is important to understand that there is a difference between being aware of the need to adapt to the online environment and being willing to pursue such strategies. These differences are outlined below. 


\section{Unsuccessful Adaptation}

Successfully adapted instructors became aware of the need to adapt strategies to the online medium, and spoke of this in connection to peer support. Proper resources are a necessary condition for helping instructors become aware of the need to make changes to their teaching strategies. Without proper support, however, instructors get by on a trialand-error basis as they attempt to make the transition to online instruction.

Instructors attempted various changes to their methods before finding the perceived best approach. Matt's eventual best approach is arguably a poor one; he said he had no choice but to lower his expectations for online students. In other words, he did not see any way that he could achieve high-quality learning outcomes, so he simply lowered the bar for his online courses. This is because he is not aware of a way to overcome the labor-intensive challenge of teaching larger course sizes in a text-based format. Where others consulted with their peers on how to teach online, Matt did not. Whether imagined or in reality, Matt said teaching online made him "radioactive" to his peers, and as a result, he lacked the resources and incentive to develop a proper online teaching strategy. This is congruent with Weimer's (2010) assertion that motivation and commitment levels of instructors will suffer if he or she feels unsupported. Matt's comment here is a good anecdote for what can happen when an online instructor lacks the proper support from his or her peers.

"I find actually, the papers are shorter and I have less expectation of quality now. Because back in-person, when I teach in-person my theory is, I'll get to know people, the coaching on writing is much more in-person and spontaneous. And the course sizes frankly were smaller, so I had more time to read each paper." - Matt 
Matt lacks an understanding of how to approach online teaching even after six years of experience. His lack of communication with his peers is one reason why he is unsure of how to proceed.

"I think we're still trying to figure out this online teaching thing, is how do you do it the right way? Nobody told me jack. They just said go start doing it. It's a very, very different experience, and spontaneity is much lower when it's not in person, and I don't fully understand why, but there is just no doubt in my mind that that is one aspect that's different... I think that you can't just graft the old format and material into the new format and expect that it can all work, you know, just dandy because it's a different animal." - Matt

Matt notes the larger size of his online courses as a reason for why his old strategies are ineffective. To apply his F2F strategies to the online format - wherein he provides students with in-depth one-on-one support on things like writing - he would have to have the help of teaching assistants.

Like Matt, Jacky recognizes the need to "find new tools" for teaching online, but she lacks the proper resources to find such tools. Despite her lack of confidence in what strategies work best online, she is still confident that online learning is valuable, but she is still in search of proper online teaching strategies. Despite the fact that she has been teaching online for almost five years, Jacky lacks an awareness of how to do things differently.

"I don't think I've been able to transform completely, for various reasons. I have difficulties envisioning [teaching] in a new way... When I first taught it in the fully online environment, that particular course that I mentioned really suffered without the opportunity to speak about the books and the readings. And that was true because these were particularly challenging readings. And that's where I think having the supportive apparatus of the face-to-face and being able to provide the kind of context on the spot that would help students to make sense of 
the readings, and, again, kind of help them with follow-up questions. All of that proved to be very challenging, and that's been the one thing that I have not solved. I have not figured out, what can I substitute for that? If anything?" -Jacky

Thus, the transition to teaching online is characterized by trial-and-error. However, instructors who have access to particular resources have an easier time transitioning.

\section{Successful Adaptation}

For those who become aware of the changes in online instruction - to change their role from teacher to facilitator, incorporate asynchronicity into pedagogy, and accommodate larger course sizes - the key to the transition is resources: peer support, technical support, and access to teaching assistants

\section{Peer Support}

While instructors occasionally need a helping hand via technical support or access to teaching assistants, peer support is far more critical to their success with online instruction $^{2}$. If an instructor is to apply persistent commitment to teaching online, they need to feel like their effort is valued by their peers. They also need peers who are informed about teaching online and can offer pedagogical advice.

Darcy explains that her success with teaching online is in part due to the support from her department and the confidence that her peers have in her as an expert online teacher.

\footnotetext{
${ }^{2}$ In fact, all respondents have a firm grasp on navigating the technology by this stage in their online teaching experience. They concede that technical support is there when and if they need it.
} 
"Our program is really good about saying you as a professor are a content expert, and no one else, we have this whole team, and everyone has their respective roles. And it's been working really well because of the fact that everyone is compensated fairly and well, everyone understands their role, everyone understands that any weak link could jeopardize not only the course but the program." - Darcy

Nicky also acknowledges how critical peer support can be, both for pedagogical and emotional reasons.

"Finding ways to not be isolated in teaching [is important]. Having some kind of peer group, or working with a small group, or some connection with your supervisor, I think that is important, I didn't realize as much when I first started." - Nicky

Nicky feels online teachers must be more committed to the online classroom than they are to the in-person one because the face-to-face format has a higher "baseline". What she means by this is that simply by being physically together creates an advantage in terms of making the teacher-to-student and student-to-student connections that are critical for successful learning outcomes. As a result, online teachers have to make more of an effort to create an interactive learning environment. Aside from the pedagogical necessity of being committed, Nicky notes that online teachers also must be committed because now that Portland State has had online learning for some time, the teachers are the ones who construct the course - "You know when I started back in 99 and 2000, the IT person did just about everything for you. And now, it's almost the other end." Having rapport with a group of peers who understand online teaching is one way to deal with the added responsibility of building an online course. 


\section{Teaching Assistants - A function of time}

Aside from the technical support -to solve technology-related problems - and peer support - to have confidence in developing a strategy for teaching online and incentivize the increased labor - online instructors also need a very practical resource: Time. Five out of the ten respondents use teaching assistants in their online courses, and they describe this as a critical resource for delivering quality instruction. Teaching assistants solve several problems: 1) they make facilitating discussion feasible in the much larger courses by breaking down the course into smaller groups and assigning an assistant to each one, 2) they ensure that every student gets personalized feedback on their work, and 3) they disperse the burden of providing technical assistance to students across a team of teachers, rather than a single instructor.

"[Teaching assistants] are essential. They are not just important, I would elevate them to the status of essential. We couldn't offer the quality of service that we do without the graduate facilitators. They take a lead role in those discussion groups, you know they are a tremendous help with grading, they are really good at reminding students of the resources." - Darcy

Acquiring teaching assistants requires funding for graduate students, and many respondents explained that a lack of funding from their department is the reason why they could not have teaching assistants. However, Karen has proven that a lack of funding does not mean teaching assistants are out of reach. Her imaginative approach led her to realize she can simply ask her brightest undergraduate students to assist (albeit pro bono) with her future courses. 
"Every term I asked my top students, top in terms of not only their scores on different assignments, but also who is most active in the discussion areas. I ask them if they will come back and be my undergraduate assistant. Obviously, I have 7 TA's, and they aren't going to give me 7 graduate students, so I always ask my best undergrads to come back [and we] work as a team." - Karen Conversely, if an instructor cannot access teaching assistants, online interaction suffers or is lost completely.

"When I have TA's, we have a discussions board and the TA's run that. When I don't have a TA, we don't. So, they don't interact with each other as much. It isn't feasible to run a discussion board in a large course when I'm on my own." Maureen

\section{On-Campus Presence}

There is strong evidence to suggest that retaining face-to-face courses is critical to adapting to online learning. In this way, the ability to continue teaching in-person in addition to teaching online is considered a resource. All but two of the respondents say they feel they have successfully adapted to teaching online. The two who have not adapted - Jacky and Matt - are the only two who teach exclusively online courses and lack departmental support/ peer support (whereas Nicky lacks a F2F course, but feels supported by her department). Jacky chose to move away from Portland, thus making the conscious, practical decision to only teach online. Matt did not choose to only teach online; he was asked to teach online by his department, and eventually, he was no longer needed for F2F teaching. Yet despite the different reasons for only teaching online, the result is the same: they both bemoan the loss of performing in-person and using their lecture skills. It seems in order to be truly satisfied with teaching online, instructors must have an outlet for their more traditional teaching methods. In this way, having the option 
to continue teaching in-person is an important resource. It came through in the codes that those who retained a F2F course spoke of it in connection to innovating strategies or as an outlet to workshop their teaching methods. Those who did not retain an on-campus presence had far fewer interactions with others predicated on their role as a professor, especially if they lacked support from their peers. Continuing to teach in-person curbed the feeling of loss that respondents had for the lack of spontaneous, informal interaction in their online courses.

"I would say it's perhaps just made me more, to teach online and then go back to teaching on-campus, has made me just more aware of the way my courses are structured and making sure that students are getting enjoyment out of that. I don't want them to just sit there and feel they have to sit through a lecture and this boring. So I think the interaction, I've continued to keep this interaction of discussions and activities and things like role playing as a part of my classroom experience." - Naomi

Others described teaching online as a rejuvenating process in which they re-evaluated what they previously thought possible in the in-person format. Respondents appreciated the intellectual challenge of teaching online; the transition to teaching online forced them to question their methods, where they may not have if left unchallenged.

"It's kind of funny that the more I do the online I'm much more selective and careful with what I use inside of the course... the changes that I've seen in myself, and in my students, just more willingness to explore what I can do, you know we came in with this mindset that you could only do what has been done in the past. I think the mobility, the mobile classroom, I like that idea that learning can take place anywhere, in that it's not... we're not limited to the classroom, and obviously in the campus environment maybe you'll go to a coffee shop or maybe you'll have course out in the greens somewhere, maybe in a park, but for the most part you're in a classroom. So the pedagogical shift for me has been to constantly to remind myself that we're only limited by our own imagination. There's really nowhere that we can't go." - Darcy 
Retention of an in-person course is one way in which online teaching can be a revitalizing experience. This can be an important milestone on the path to reconsidering the meaning of instruction. However, there are other factors that contribute to meaning changes, such as one's personal history.

\section{Personal History}

When asked about what it was like to teach online initially, many respondents volunteered information about their personal history. Karen explains that her history with computer science made the use of technology fairly easy. When asked if she feels she was provided with enough training to begin teaching online, she says,

"I think because of my experience with computers and who I am, just how I work, the answer is yes, I have been." - Karen

Rob says that his background as an attorney made him very accustomed to team teaching.

He explains that his professional training was always geared towards sharing responsibility, and this makes it easy for him to give instructor-level authority to his graduate assistants.

"I feel very comfortable in team environments. I had a trial team when I practiced. You have to share authority in a team setting, and that means you're no longer the voice of authority in charge. And I think to be really effective in an online environment you have to figure out some way where you're going to have to effectively delegate, especially if you're teaching 240 students, and you can't lecture to them. How are you gonna engage in communication? Well, the odds are overwhelming that you're not going to be able to do it exclusively yourself. So I think my background coming into it, having the team teaching, having a conversational format, made it easier for me to do it. Certainly made it easier for me to shift to the format that I use now with the co-teacher approach and the graduate students, because I feel comfortable." - Rob 
Prior to teaching online, Maureen expected students to work independently and take responsibility for their own learning; when students have difficulty with learning online, she does not feel at all to blame. She explains that the online classroom "presupposes an advanced level of reading and writing" and if students do not understand this when they enroll, then it is their own fault. She explains that she has never felt responsible when a student fails at self-regulation, and this has served her mental well-being in the online classroom.

\section{Adjuncts}

It should be noted that four respondents are not currently tenure track, and categorize themselves as adjunct instructors. While it seems logical that this would be an important factor in an instructor's transition to teaching online, the data simply does not provide this connection. However, there is a connection between being an adjunct and a lack of resources. A few (Jacky and Matt) feel they are unfairly compensated, and they consequently lack a financial incentive to put forth the time to teach online. Adjuncts are also the respondents in this study who over represent those who lack teaching assistants. However, in considering Karen's (an adjunct) innovation in acquiring her own assistants, being an adjunct does not appear to have a direct relationship with the valuation or devaluation of teaching online. Rather, being an adjunct affects access to resources and environmental factors, and these in turn have an impact on how an instructor experiences the online classroom. 


\section{Considering the Experience in Retrospect}

Respondents who have the awareness, willingness, and resources to adapt to teaching online view the medium very positively. In fact, when asked, "do you enjoy teaching online?" all respondents said they did. Even those who had not been able to fully adapt to teaching online - Jacky and Matt - enjoy teaching online on some level.

\section{Self-serving reasons}

However, the reasons why Jacky and Matt enjoy teaching online are somewhat self-serving. Jacky, for example, feels the benefit of being untied from the campus makes up for what she perceives as an unfair wage. Additionally, Matt - an adjunct instructor likes teaching online because without it, he feels he could be out of a job.

"...the flexibility is also useful, so in some ways, you know, I think I don't have to be as sharp online. That can be a comfort when you're busy and you have a lot going on, and just like for the students, I can sit in my pajamas and write to my students, or I can be in a coffee shop. I can live [outside of Portland]." - Jacky

"So I feel like my job security, which is never great as an adjunct, is [better]...And my suspicion is a lot of us are adjuncts and it's probably a gold mine economically for the school." - Matt

\section{Student-serving}

On the other hand, all other respondents in this study enjoy teaching online because they feel it is a real service to students. Respondents describe a feeling of pride for being able to reach individuals for whom college would not normally be an option. 
"There's a community and a population that really benefits from online experience, I am excited [about that]. We serve people that would otherwise never have a college degree, and that I'm really excited about." - Rob

"I realize that students do prefer the online world because it's much safer for them. And sometimes they can blossom actually, without the pressure of social interaction." - Jacky

\section{Changes in Teaching Philosophy}

On the whole, respondents in this sample take great pride in teaching online. For many respondents, teaching online deconstructs the hegemony of traditional teaching methods. Major (2010) finds that the opportunity to use new teaching technologies and experience a new intellectual challenge is a rewarding experience for instructors.

Similarly, respondents in this study explain that the online medium forces them to reconsider the role of the instructor, and also what is possible both online and F2F.

"I have been saying for years that I think I'm better suited to teaching online than in the classroom, and I think that's because... well, why is that? You have to be somewhat of a performer in the classroom, and I think I like being more behind the scenes. I like being able to really able to think about what I want to say and how I want to say it. Which, working online gives me the ability to do that." Karen

"Well, you know honestly I sort of enjoy the challenge of thinking how can I stimulate learning and interest in different ways? And, it's just another way of, and I do the same with in-person teaching too, so it's just another way of posing yourself challenges to get content and material across to students, to try new techniques of learning, new assignments, things of that nature. So I actually enjoy that, sometimes I feel like I'm shooting myself in the foot for trying new things, or taking on new things, but I think it's good. It keeps me fresh, and it keeps the courses fresh." - Brad

"I wish I had really appreciated what this digital medium can offer and had the tools to make the leap sooner." - Jacky 
"It's no longer the University of Phoenix phenomenon. The major league players are involved in this industry, and the more we take it seriously and take up the challenge of how do we create great learning in this environment, rather than fighting and resisting it. We don't do what we do and say, we've achieved what we want to do, we'll just keep replicating it. We are constantly rethinking it and changing it. It makes it exciting. And it's fun." - Rob

Many respondents use the word "transformation" when describing what it was like to transition to online teaching. This is particularly fitting because these data suggest the transition truly is transformative. Initial skepticism of the medium gives way to a reimagining of the "old tools" and a creation of new ones.

\section{A Gradual Transition}

Adjusting to the online classroom takes time- and over time, it gets better! Not one respondent describes the transition as an easy one, and a few have not been able to "fully transform" into the new role. Respondents describe the transition as a long and bumpy road, and one that must be traveled in order to be understood. Most importantly, it is a journey which is - for some - highly transformative and results in a re-evaluation of what it means to teach. Some subjects did seek out training opportunities, but ultimately, teaching online is a "seat of the pants operation" (Matt). In other words, the learning happens through doing. This process is not an easy one in part because of pedagogical challenges, but also because instructors face pressure from several sources in their professional community. Most faculty support voluntary enlistment for teaching online, but it is clear that for some of the respondents in this study, they were incented or nudged into it. Further, they cannot fully understand the meaning of "volunteering" to teach 
online because they have never before attempted it. There is also the lingering question of intellectual property rights. Instructors must make a weighty investment in structuring the organization of their online courses, and it is unclear - at least at Portland State - whether the course then belongs to the instructor or the institution. Instructors also feel pressure from the academic community; some respondents perceive the academic community feels online learning should be relegated to the realm of for-profit schools and non-elite students.

The magnitude of this trial-by-fire period is curbed with the proper provisions especially peer support - that make instructors aware of how to change. However, while proper resources help ease the transition, it is ultimately up to the instructor as to the degree to which they will commit to teaching online. This is a critical phenomenon, as respondents in this study as well as relevant researchers explain that instructors must make a substantial time commitment to teaching online (Conceicao 2006; Major 2010). Compounding the difficulty of committing to teaching online is the ever-present threat of change. In the last five years, for example, Portland State has changed learning software three times (moving from WebCT to Blackboard, and finally to the current suite, D2L). Thus, even if an instructor masters the software, it is likely that a new platform must be learned sooner rather than later. The mechanism of commitment, then, deserves elaboration. 


\section{Willingness and Commitment}

Respondents spoke of their commitment to teaching online (or lack thereof) as a function of time spent laboring in the format versus the in-person one. When asked if they spend less, as much, or more time teaching online than they do in-person, all but one respondent (Matt) reports spending more time teaching online. Furthermore, respondents in this majority group truly value their online interactions with students.

\section{Importance of $F 2 F$ teaching}

Stryker and Serpe (1982) explain that the salience of one's identity and relevant commitment to that role is strongly influenced by the location of "online instructor" in one's personal hierarchy of roles. This is evidenced by some respondents singing praise for teaching in-person, and feeling at a loss when teaching online; the medium is fundamentally different, and so too is the role. Thus, respondents who have a particular flair for the spontaneous, emergent nature of the in-person classroom will have a harder time feeling as passionate for the formal and static nature of the online classroom.

"With all due humility, I'm a really good teacher, and sometimes I've felt, and I think I felt this more in the beginning, that my expertise, knowledge base, and personal charisma, were completely absent, and there was no place for any of those things in the online environment...I think [being in-person] makes it much more personal, and, by its nature, much more interactive... I think they miss out on the skills that I bring to my teaching, because I've got a lot of experience and enthusiasm for it." - Jacky

This shows, as noted earlier, that retaining a F2F course is important. The earlier discussion of it shows how retaining an on-campus presence leads to revitalization of one's professional satisfaction. In this context, however, it is clear that retaining an on- 
campus presence is important for sustaining one's passion for teaching. In other words, an instructor may not feel as conflicted about his or her online teaching identity if an inperson or "traditional" teaching role identity is maintained.

\section{Appreciating online relationships}

Identity salience and commitment are also influenced by the extent to which significant social contact is based on a particular identity (Stryker and Serpe 1982). A few respondents explained that they actually have closer teacher-student relationships with their online students than they do with their in-person students. This is because 1) an online course provides $24 / 7$ connectivity and 2) online interaction is seen as an acceptable substitute for F2F interaction.

"I have found that I have in some cases almost a closer connection with the online students than the students on-campus. I've gone sometimes weeks with nobody coming to office hours, you know?" - Naomi

"I'm furthering a relationship with each of those people, and some of those have turned into lifelong friendships, I think. When I'm teaching in the classroom with 300 students a term, there are maybe one or two students who I actually get to know their names, and by the following term, I can't remember who that was. So even though I've never met some of these people, there are some really good relationships that we've got going." - Karen

However the key to this is the belief that online interaction is valuable. Matt, for example, feels differently than Karen and Naomi about the relationships he has with his online students because he does not seem to value online interaction. As a result, he views online learning unfavorably, which is a factor for his lackluster commitment to teaching online. 
"I would say that in general I have mostly not liked it. It's not as, part of it is just selfish, because it's not as fun or fulfilling for me as a teacher. You don't get to know people. Over time, I've had people that have taken 6 or 8 courses from me all online and I've never seen them, and I end up being kind of friends with them, but still you've never seen their face, you wouldn't know each other if you walked past each other. That bothers me somewhat." - Matt

\section{Conclusion}

In the end, eight out of ten respondents in this study feel the online classroom facilitates their teaching responsibilities as well as the in-person classroom.

"I know that in the beginning when I started teaching there was a lot of resistance in general to online teaching because somehow the perception was that that is not as valid a way of learning, it's not the same quality as you're getting in a classroom. And I would, for whoever might have that opinion, I strongly disagree with that. The quality that I teach online is the same as the quality in the classroom, and I don't think there needs to be any variation on that at all, in terms of you can offer exactly the same quality. You might have to restructure a bit, but I think it's there." - Naomi

Naomi's feeling of the quality of online learning exemplifies the feeling of the majority of this sample. If given proper resources (especially peer support), instructors can become aware of the best online teaching strategies. If made aware of an effective online pedagogy, respondents will gradually adapt to teaching online by using these new strategies. If the instructor has peer and departmental support, he or she will begin to persistently commit by investing an appropriate (that is, high) amount of time. If the instructor lacks departmental support, adapting and committing is difficult; two respondents in this sample have a sordid relationship with teaching online because of professional concerns. Matt says teaching online made him "radioactive" in his department. Jacky says the "pay is shit". Clearly, then, fair pay and support from your 
colleagues is key to having a positive online teaching experience. As Portland State continues to improve the support and compensation for teaching online, this feeling of solidarity and commitment to online learning will likely flourish across campus. 


\section{CHAPTER 6: DISCUSSION AND CONCLUSIONS}

This section gives a summary and synthesis of the findings, placing them within previous theoretical and empirical research, and discussing the implications of these findings in terms of adapting to the online classroom and the future of teaching online. I will also discuss areas where this research brought to light certain questions or findings in need of future research.

Upon examining the transcripts and constructing the codebook, some primary themes emerged. First, the role of an online instructor is different from an in-person instructor. Instructor responsibilities are different and more time consuming online than they are in-person, and this demands an adaptation on behalf of the instructor. Secondly, this adaptation is predicated on the awareness of effective online teaching techniques and being committed enough to online learning to pursue such strategies. For these to occur, online instructors must possess a salient online teaching identity and sufficient commitment to the medium. Third, peer support and practical resources such as teaching assistants expedite the process of adaptation and commitment to teaching online. Finally, and contingent upon the degree of success of adaptation to the online classroom, teaching online leads instructors to rethink what it means to be a teacher, what is possible in the classroom, and the purpose of higher education.

\section{Adapting to New Responsibilities}

The online classroom is always computer-mediated, and is usually text-based. Relevant research suggests that online teaching is in its rudimentary stages, and there is 
no practical way to overcome the text-based nature of the online classroom (Levine and Sun 2002; Major 2010). Furthermore, interaction in the online classroom is usually asynchronous, which means students decide where and when to "attend" course and when to participate in the discussion. This diverges from the in-person classroom in which students attend course and participate in discussion at the same time in the same place. Respondents explain that the fundamental change in the nature of interaction across the two mediums results in a shift in the instructor's responsibilities. Because respondents and relevant research indicates that teachers teach how they were taught, the online classroom is a foreign endeavor for instructors trained prior to the online learning boom $^{3}$ (Norton and Hathaway 2008). For respondents in this study, the computermediated, asynchronous, text-based classroom initially left much to be desired. Specifically, instructors struggled with a sense of loss of spontaneous, emergent dialogue that is at the core of working with students in a synchronous F2F discussion.

The online instructors in this study speak passionately about the spontaneous nature of F2F teaching. Lecturing is a challenge because it requires the instructor to master a performance-driven way of teaching; instructors have to find a way to be engaging for learning to take place. But despite this challenge, respondents say that what makes them high quality in-person teachers is their ability to lead an emergent and engaging discussion. Rather than suppressing spontaneity, these instructors embrace it. They feel that when students interject with comments or questions - even if they are not

\footnotetext{
${ }^{3}$ Harasim (2000) argues that 1999 marked the year in which universities across the country began implementing online learning.
} 
well thought out - everyone benefits. Encouraging students to interject when clarification is needed reduces confusion about course content.

After transitioning to the online format, instructors reflect on F2F spontaneity and consider it a privilege. This is because, as Coppola, Hiltz, and Rotter (2002) also find, inperson teaching tools are less relevant in the online medium, necessitating the creation of new ones. In-person instruction is driven by sensory and expressive methods like calling on students who - based on body language - do not seem engaged (Brad, Naomi, Nicky, and Jacky). Major (2010) agrees that in-person teachers rely on nonverbal cues from their students; they have trouble feeling assured about student engagement in the online format. Online students interact with information and "virtual people" (Major 2010). As a result, online instructors need not provide an engaging performance, but rather must envision and produce an entire online course from start to finish before the course begins (Brad, Darcy, and Rob; Kanuka, Collett, and Caswell 2002). Mead's analysis of self is useful for putting this interactional shift into perspective. The difference between the structured and agentic elements of the self is an important distinction to understand. Mead (1934) explains that the self is discovered through social interaction and is reflexive. Individuals shape and reshape their behavior in response to the behavior of others. The self is highly dynamic, and seeks approval from the relevant community. I made the claim earlier that in the classroom, the academically-relevant self (that is, one's instructor and/or student identity) is emergent, developed, and reinforced through interaction with others via discussion. This is true in both classroom mediums, but in two 
different ways; respondents indicate that the online medium alters the very nature of interaction. This is because two distinct and separate elements make the self: The "I" and the "Me".

The "I" refers to the spontaneous, creative, and improvisational elements of self; it is the part of the self that manifests surprising results to both the actor and the audience. When instructors speak of teaching in-person, the subtext is that the improvisational and emergent aspect of teaching and learning is highly valuable. From the respondents' perspective, the improvisational aspect of teaching is extremely meaningful and satisfying. From the learners' perspective, the dynamic nature of the in-person classroom affords them an opportunity to ask questions when confused. Although these spontaneous interjections are sometimes not well thought out, respondents say this is helpful; a student may ask a seemingly "dumb" question that other students wanted to ask, but were too afraid and thus are inhibited.

In the asynchronous online format, the spontaneous elements of self - the "I" - is greatly reduced. Respondents explain that students are less likely to make short, informal comments online than they are in-person. This is problematic for these respondents, as they feel students may not be asking questions as they arise. Jaffee (1997) would disagree that the "I" is curbed in online discussions; his results indicate that online discussion actually yields more of this kind of informal cross-questioning because computer mediation eliminates much of the anxiety associated with the "public expression of ideas and opinions," (271). However, this more methodologically rigorous study is more valid 
considering that Jaffee's (1997) work is a narration of his personal experiences with teaching in-person and online.

The "Me" refers to the stable elements of self that are based on an understanding of what others expect to happen in an interaction. The "Me" is highly cognizant of the community expectations for how an interaction should proceed. In the asynchronous online classroom, interactions are much like the "Me" than they are the "I" because students interact at their own pace; in this way online discussion is highly reflexive, and more so than an in-person discussion. Within reason, students have time to formulate a response, reflect, and revise before executing their response. This removes the possibility of students feeling "put on the spot" if they are called on by the instructor in a F2F discussion. This is one reason why many respondents as well as other researchers note that the online discussion board yields high quality work (Karen, Nicky, Brad, Naomi, Rob, and Darcy; Russell 1997; Jaffee 1997; Hampton and Wellman 2001; Persell 2004; Baglione and Nastanski 2007)

In the face-to-face medium, human response is an interpretation of behavior guided by reflexive logic, or a sort of internal dialogue. This process is heavily influenced by the face-to-face emergence of the generalized other (which in this instance would be the students to whom the teacher is delivering content). The organized response of students-to-teacher and students-to-students has indeed been impacted by - or is transformed within - virtual space. The organized response process is transformed when teaching online as compared to teaching face-to-face, particularly the ways in which 
isolating the "important parts" - that is, observing student response to stimuli when you cannot physically see them - becomes a foreign endeavor. Kanuka, Collett, and Caswell (2002) allude to this when they explain that moderating an online discussion does not feel intuitive to instructors who have expertise in the F2F classroom.

Consequently, those with expertise in the F2F classroom feel that the platform "automates" their job (Conceicao 2006) and in turn, the instructor is no longer central to the learning process. To an extent, this is true for this study; respondents explain that they must make decisions about when and what to teach before knowing their audience, whereas in a F2F course they can adjust their strategies "on the fly". Respondents imply feeling helpless when students get behind. In the F2F medium, helping students catch up is easier compared to the online medium. If students fail at self-regulation online, instructors find it difficult to re-engage them. As a sort of practical self-defense mechanism, many respondents (Rob, Brad, Darcy, Naomi, Maureen, and Matt) displace the responsibility for student outcomes from themselves and to the students. By expecting learners to be highly autonomous, instructors avoid feeling guilty when students do poorly. Moore (1972) suggests that instructors evaluate the level of independence of each student and subsequently address their needs. However, respondents in this study indicate that this level of one-on-one engagement is not practical because of the larger course sizes. Instead, online students simply must be capable of self-regulation. Those who are not are more suited to F2F learning. 
In part because engaging students is more difficult in disembodied space, instructors interpret feeling "automated" because they must relinquish some degree of control of their course. In terms of Mead's conception of self, this automation reduces some element of a whole self as they had to come know it. In the F2F format, instructors deliver lecture and moderate discussion; in other words, the in-person instructor is the "master of ceremonies". In the online format, however, instructors simply post content, respond to messages, and grade assignments (and they will indeed have more grading to do if they decide to make the discussion board mandatory). Respondents in my study and relevant research (Smith et al. 2002) suggest that online instruction is less about teaching and more about facilitating. Instructors must no longer be proficient in the expressive performance of F2F lecture, but rather must be detail-oriented masters of the learning technology. In-person, teachers teach; online, they facilitate.

This change in responsibilities is a concern for respondents in this study in part because of the nature of their disciplines. These respondents are social science instructors and find human interaction to be central to their methods. Faux and Black-Hughes (2000) quantitative research also finds that, in comparison to other areas of study, the social sciences are difficult to teach online. Abstract concepts - such as Mead's conception of self - are difficult to teach in-person as well, but the in-person classroom facilitates a multitude of learning styles. Namely, in the F2F classroom, respondents use small group discussions to help students explain and form their understanding of course concepts. Clark-Ibanez and Scott (2008) agree that discussion leads to greater learning outcomes, 
and small group discussions are one way of implementing this. While many respondents formed small discussion groups online, they admit that it is not the same as doing so inperson. Respondents explain that online discussion is actually more analogous to short writing assignments, and does not facilitate various learning styles like in-person small groups; instead of listening to their peers, online discussants are reading their work, and instead of speaking to their peers, they are writing to them. Thus, social science instructors (in particular) face hurdles in the online format because of the preference for human interaction.

\section{Awareness and commitment}

New responsibilities in the online classroom mean online instruction is a different role than in-person instruction. However, this is not inherently negative, even if online teaching feels automated. In fact, so long as conditions are right, teaching online can be a powerfully rejuvenating experience for university instructors. A number of factors influence the degree of this rejuvenation and subsequent level of commitment to the medium. Primarily, highly committed respondents spoke of the importance of the support and encouragement they received from their peers. Namely, instructors who have a familiar group of peers with whom to collaborate on online teaching methods fare better in the process of transition. These findings support Weimer (2010) who finds that instructors need to feel their efforts are appreciated in order to make the appropriate time commitment to teaching. Peer support is crucial in order for online instructors to feel 
professionally legitimate, for reducing the trial-and-error period of teaching online, and for hastening the process by which instructors become aware of how to teach online.

Certain resources lead to the discovery of new teaching methods and subsequent high commitment. Not surprisingly, practical support in the form of teaching assistants is an extremely important resource because the online medium is more time consuming for instructors (Conceicao 2006). Instructors need assistants to manage and curate online discussions, which must be read rather than heard. Adjunct instructors will have to work harder in this regard because they often lack access to teaching assistants; they must be innovative - as Karen does - in their search for assistance. If instructors are have access to departmental or peer support and teaching assistants, they are primed to become highly committed to teaching online. However, there is another important resource needed to become committed to teaching online.

To become well adapted and committed to teaching online, instructors must be able to retain a F2F course in addition to the online ones. This is a key finding that is not seen in the relevant literature. Retaining at least one in-person course is critical in order to view online learning positively and to curb the feeling that online teaching is an automated form of instruction. If they were able to retain a F2F course, teaching online forced respondents to rethink their in-person methods. Teaching online made them realize that the classroom in both mediums could offer much more than lecture and discussion. For example, after transitioning to online teaching, Darcy incorporated elements of her 
online courses into her in-person courses ${ }^{4}$. If they had not already done so prior to the transition, respondents began to relinquish control in their in-person courses as they realized that assignments in which students have greater autonomy helps them grow as self-sufficient adults.

\section{Perception of Self and Higher Education: A Fundamental Shift}

Those who became committed to teaching online (eight of ten) experienced a sea change in what to teach and how to teach it. By relinquishing control of the course, instructors began to see the value in helping students grow as independent, self-sufficient learners. Instead of content mastery, well-adapted and committed instructors emphasize imparting skills to students that will help them become autonomous self-regulators who will be successful in their adult lives. This perception shift changed how the respondents viewed the purpose of higher education. In turn, instructors truly embrace the medium, rather than simply tolerate it. Be it self-serving reasons - like the convenience of teaching from home - or for student-serving reasons - such as the possibility that the skills gained in the online classroom are more relevant students' future adult lives - instructors come to enjoy teaching online. Furthermore, it is evident that this is a gradual process. It takes time to become satisfied with teaching online. Over time, however, highly committed respondents come to truly value relationships with their online students. Major (2010) also finds that, as compared to interacting face-to-face, closer and more intimate connections may occur in disembodied interaction. Respondents who value their online

\footnotetext{
${ }^{4}$ In the online format, she often asked students to gather information from several different websites and then synthesize them into a report. She later began assigning this to her in-person students in order to help them grow as independent self-regulators.
} 
relationships note that they have more frequent and more revealing interactions with their online students than their F2F ones, which in turns strengthens the salience of their online teaching identity. On the other hand, those who are not committed to the online medium note their online interactions are of reduced quality and quantity. This is supported by Stryker and Serpe (1982) who explain it is difficult to become committed to a role if there are not frequent and significant interactions based on that role (in this case, interactions between teacher and students premised on the teacher's role as an instructor).

Those respondents who feel particularly strong about their in-person teaching ability - namely, Jacky and Matt - also are among those who value computer-mediated relationships the least. Jacky and Matt spoke repeatedly of how important it is to them to teach in-person. It makes sense that if an instructor spends years forming and reforming his or her in-person "performance", then teaching online would be a tough pill to swallow. The other eight respondents also possessed a salient in-person teaching identity (although they mentioned it far less), but they were able to continue teaching in-person. In addition, these eight respondents note that they value their computer-mediated relationships with students. Continuing to teach in-person provided them with a familiar space to practice the expressive way of teaching, and did not leave them feeling yearning for F2F interaction. This, in turn, led them to value their online relationships. Jacky and Matt were not able to retain an in-person course, and their commitment levels suffered consequently. By only teaching online, they have no outlet for their painstakingly developed in-person methods and feel considerably disadvantaged. This is an 
overwhelming feeling that caused Matt to lower his expectations for his online students and withdraw his commitment to the medium via reduced time investment. As Levine and Sun (2002) explain, there is a general lack of knowledge among online instructors about what works well. If instructors have proper support and resources, they can discover what works and what does not. In turn, they will rethink what it means to be an instructor and what the students should gain from college. However, without the proper resources - including the retention of a F2F course - the trial-and-error process will be long and arduous, and may leave instructors feeling unsatisfied and suspicious of the online medium.

\section{Conclusions}

In the end, those instructors who were properly supported and came to be highly committed to teaching online report several advantages. The asynchronous discussion board allows instructors to receive and respond to responses from every student, rather than a vocal few (Jaffee 1997). It eliminates the anxiety that some students have towards public speaking (Smith, Ferguson, and Caris 2002). Respondents note that the 24/7 connectivity of internet - while sometimes laborious (Lao and Gonzales 2005; Conceicao 2006) - can lead to higher quality relationships with students (Hampton and Wellman 2001).

However, even highly committed respondents note some disadvantages. It seems likely, as Faux and Black-Hughes (2000) also found, that the social sciences are particularly challenging to teach online. This is in part because an asynchronous online 
course is devoid of the spontaneity of a F2F course that instructors find very useful (Kanuka, Collett, and Caswell 2002). And because the online classroom is not synchronous, some of the decision-making previously made by instructors - such as when and where to attend course - is instead made by students (Andrews and Haythornthwaite 2007). In turn, some instructor authority is given to students, which can be difficult for those who feel the instructor is the "master of ceremonies". This can have negative consequences, however, as Williams and Hellman (2004) find that learner self-regulation is especially critical to successful learning outcomes in the online format. Instructors cope with this by expecting students to be highly self-regulatory, and do not fault themselves when students fail at autonomous learning. This is problematic, however, as there is no evidence to suggest that these respondents communicate the necessity of selfregulation to their online students at the start of the course.

For the large majority of respondents, the advantages of online instruction outweigh the disadvantages. Once instructors are able to accept the new technology as a suitable tool for successfully executing their task (Gibson, Harris, and Colaric 2008) they come to appreciate teaching online. In the case of asynchronous discussion (which is a primary focus of this study), instructors come to accept the dominance of the "Me" - the stable and predictable - over the "I" - the spontaneous and emergent (Mead 1934). Baglione and Nastanski (2007) surveyed 303 online teachers and found that 50 percent like both mediums equally and 29 percent prefer teaching online to teaching in-person. The respondents in this study represent an even greater affinity for teaching online, with 
eight of ten respondents reporting the same affinity for teaching online as they have for teaching in-person, and with two reporting a preference for teaching online.

\section{Limitations}

While these data give a rich, in-depth look at teaching online, this study is not generalizable to all online instructors at all universities. One important caveat of this research is the location in which it was conducted. The average age of a Portland State student is 28 , and many work part- or full-time in addition to carrying a full course-load (Portland State Fact Sheet). Driscoll et al. (2012) finds that, in general, students who enroll in online courses are older than the average age of on-campus students. I lack the data to say for certain, but this may be also true for PSU. If so, then online courses at PSU are composed of students who, on average, are older than the campus-wide average (28 years of age). Thus, the students - a central factor in instructors' evaluation of teaching online - are unlike students at other universities. In this way, the results of this study are transferable to online social science instructors at other urban universities with demographically similar students. Furthermore, as is the case with qualitative research, the non-probability sample selection could reflect my own subjectivities. Similarly, qualitative coding also poses the possibility that results are the interpretations of an individual researcher. As a result of time and resource constraints, these data lack intercoder reliability, and the results are consequently subject to my biases. However, I hope that through the grounded theory method, I let the respondents dictate which data are most significant. 


\section{Future Research}

This research topic is one that is rapidly changing. Even as I type these words, I have no doubt that researchers are making discoveries that will change the field. Thus, because of the rapid changes that are happening in online learning, this topic warrants ongoing investigation. Furthermore, because this study used a small, non-probability sampling method, a study employing a larger, randomly selected sample is warranted. Of particular interest for future online learning researchers should be the segment of my sample who did not participate; Of the 35 eligible individuals, only 15 responded to the call to participate. This volunteer-based enrollment no doubt created a sample which is biased towards the favorability of online learning. Those 20 individuals who did not respond to my e-mails are extremely important to this area of study because they are likely in the camp of non-committed online instructors. This is the group of instructors that deserve careful attention in order to improve online learning outcomes both at Portland State and at similar universities.

A study examining the differences between instructors who use "live", synchronous online discussion in comparison to those who use asynchronous online discussion is also important. This would show the degree to which online learning can be like F2F learning, or if instructors should attempt to replicate synchronicity online. This study also warrants an investigation of teaching online when the class sizes are comparable to in-person classes; this would explain if the grievances of teaching online are more about pedagogical concerns, or simply practical logistics. A study comparing 
the experiences of social science instructors and instructors of other disciplines will also help strengthen or refute the argument that teaching online is particularly challenging for those in the social science disciplines. Furthermore, and in leaving separate disciplines aside, there lacks a methodologically rigorous and conclusive study which explains whether or not online learning can produce the same quality learning outcomes as F2F learning. While it is a question I attempted to avoid in this research, it is a question that must be answered.

Another important area in need of study is role changes in the online platform. The present study established that role responsibilities for faculty change in the online environment. While it is clear that these respondents expect their online students to be highly independent, the other ways in which the student role changes is mysterious. In an in-person course, students take on multiple roles at once; they mentor other students who need help, they model how to engage the course content, and they help the instructor move along through the discussion. Without having data from students themselves, the extent to which student responsibilities change in the new medium - outside of a need for increased learner autonomy - is less clear. 


\section{BIBLIOGRAPHY}

Allen, Elaine and Jeff Seaman. 2009. "Learning on Demand." Created for the Sloan Consortium on Online Learning USA: Babson Survey Research Group.

Andrews, Richard and Caroline Haythornthwaite. 2007. "Researching the Impact of Online Professional Development for Teachers." "E-Learning and the Reshaping of Rhetorical Space." The SAGE Handbook of E-Learning Research:179-199, 466-483.

Baglione, Stephen L., and Michael Nastanski. 2007. "The Superiority of Online Discussion: Faculty Perceptions." The Quarterly Review of Distance Education 8(2): 139-150.

Bernstein, Basil. 1986. “On Pedagogic Discourse.” In J. G. Richardson (Ed.), Hand-book of Theory and Research for the Sociology of Education. New York: Greenwood Press.

Burke, Peter J. and Jan E. Stets. 2000. "Identity Theory and Social Identity Theory." Social Psychology Quarterly 63:224-237.

Cacciamani, Stefano, Donatella Cesareni, Francesca Martini, Tiziana Ferrini, and Nobuko Fujita. 2012. Computers and Education 58: 874-884.

Conceicao, Simone C. O. 2006. "Faculty Lived Experiences in the Online Environment." Adult Education Quarterly 57(1): 26-45. 
Coppola, Nancy Walters, Starr Roxanne Hiltz, and Naomi G. Rotter. 2002. "Becoming a Virtual Professor: Pedagogical Roles and Asynchronous Learning Networks." Journal of Management Information Systems 18(4): 169-189.

Clark-Ibanez, Marisol and Linda Scott. 2008. "Learning to Teach Online." Teaching Sociology 36(1):34-41.

Driscoll, Adam, Karl Jicha, Andrea N. Hunt, Lisa Tichavsky, and Gretchen Thompson. 2012. "Can Online Courses Deliver In-person Results? A Comparison of Student Performance and Satisfaction in an Online versus a Face-to-face Introductory Sociology Course." Teaching Sociology 40(4): 312-331.

Doise, Willem, and Gabriel Mugny. 1984. The Social Development of the Intellect. Oxford: Pergamon Press.

Egle, Lamont, Evelyn Navarre, and Cheryl Nixon. 2011. "Breaking the Rules of Discussion: Examples of Rethinking the Student-Centered Classroom." Journal of the Sociology of Self-Knowledge 4(3): 1-14.

Faux, T.L. and C. Black-Hughes. 2000. "A Comparison of Using the Internet Versus Lectures to Teach Social Work History." Research on Social Work Practice 10(4):454-466. 
Gibson, Shanan G, Michael L. Harris, and Susan M. Colaric. 2008. “Technology Acceptance in an Academic Context: Faculty Acceptance of Online Education.” Journal of Education for Business 83(6): 355-359.

Hampton, Keith and Barry Wellman. 2001. "Long Distance Community in the Network Society: Contact and Support Beyond Netville." American Behavioral Scientist 1: 476-497.

Harasim, Linda. 2000. "Shift Happens: Online Education as a New Paradigm in Learning." The Internet and Higher Education 3(2000): 41-61.

Haythornthwaite, Caroline and Barry Wellman. 2002. The Internet in Everyday Life, An Introduction. Malden, MA: Blackwell Publishing

Jaffee, David. 1997. "Asynchronous Learning: Technology and Pedagogical Strategy in a Distance Learning Course." Teaching Sociology 25(4):262-277.

Kanuka, Heather, Dave Collett, and Cynthia Caswell. 2002. "University Instructor Perceptions of the Use of Asynchronous Text-Based Discussion in Distance Courses." The American Journal of Online learning 16(3): 151-167.

Lao, T., and Carmen Gonzales. 2005. "Understanding Online Learning Through a Qualitative Description of Professors and Students' Experiences. Journal of Technology and Teacher Education 13(3): 459-474. 
Levine, A., and J.C. Sun. 2002. Barriers in Distance Education. Washington, DC: American Council on Education Center for Policy Analysis.

MacDougall, Robert. 2005. "Identity, Electronic Ethos, and Blogs: A Technologic Analysis of Symbolic Exchange on the New News Medium." American Behavioral Scientist 49(4): 575-599

Major, Claire. 2010. "Do Virtual Professors Dream of Electric Students? University Faculty Experiences with Online Distance Education." Teachers College Record 112(8): 2154-2208.

Marshall, Catherine and Gretchen B. Rossman. 2011. "Designing Qualitative Research." Los Angeles: Sage Publishing.

McShane, Kim. 2004. "Integrating Face-to-Face and Online Teaching: Academics' Role Concept and Teaching Choices." Teaching in Higher Education 9(1): 3-16.

Mead, G.H. 1934. Mind, Self, and Society. Chicago, IL/USA: University of Chicago Press.

Miles and Huberman. 1994. Qualitative Data Analysis. Thousand Oaks: Sage.

Moore, Michael. 1972. "Learner Autonomy: The Second Dimension of Independent Learning." Research in Education: 76-88. 
Norton, Priscilla, and Dawn Hathaway. 2008. "Exploring Two Teacher Education Online Learning Designs: A Classroom of One or Many?" Journal of Research on Technology in Education 40(4): 475-495.

Olson, David. 2002. "A Comparison of Online and Lecture Methods for Delivering the CS 1 Course." Journal of Computing Sciences in Colleges 18(2): 57-63

Persell, Caroline Hodges. 2004. "Using Focused Web-Based Discussions to Enhance Student Engagement and Deep Understanding." Teaching Sociology 32(1):61-78.'

Portland State University, University Planning. "Opportunity and Competitiveness for the Region: Portland State University Strategic Plan 2011-2014." Retrieved May 7 , 2012 (http://www.pdx.edu/president/sites/www.pdx.edu.president/files/Portland\%20Sta te\%20University\%20Strategic\%20Plan\%202011-2014.pdf).

Portland State University, Office of Institutional Research and Planning. "Statistical Portrait 2011-2012." Retrieved September 10, 2012. (http://www.oirp.pdx.edu/source/port1112/all_all.htm)

Russell, Thomas L. 1997. "Technology Wars: Winners \& Losers". Educom Review 32(2): 44-45.

Smith, Glen Gordon, David Ferguson, and Mieke Caris. 2002. "Teaching On-line Versus Face-to-Face." Journal of Educational Technology Systems 30(4): 337-364. 
Stryker, Sheldon and Richard Serpe. 1982. "Commitment, Identity Salience, and Role Behavior: Theory and Research Example." Personality, Roles, and Social Behavior: 199-218.

Weimer, Maryellen. 2010. Inspired College Teaching: A Career-Long Resource for Professional Growth. San Francisco: Jossey-Bass.

Wellman, Barry, Jeffrey Boase, and Wenhong Chen. 2002. "The Networked Nature of Community Online and Offline." IT Society 1(1):1-15

Williams, Peter and Chan Hellman. 2004. "Differences in Self-Regulation for Online Learning Between First- and Second-Generation College Students." Research in Higher Education 45(1): 71-82. 


\section{APPENDIX A: THE PARTICIPANTS}

\begin{tabular}{|l|l|l|l|l|l|l|}
\hline Respondent & $\begin{array}{l}\text { F2F } \\
\text { exp }\end{array}$ & $\begin{array}{l}\text { Online } \\
\text { exp }\end{array}$ & $\begin{array}{l}\text { Retain } \\
\text { F2F? }\end{array}$ & Tenure/track? & $\begin{array}{l}\text { Dept } \\
\text { support? }\end{array}$ & TA's? \\
\hline Maureen & 25 yrs & 7 yrs & Yes & No & Yes & Yes \\
\hline Jacky & 16 yrs & 4.5 yrs & No & No & No & No \\
\hline Karen & 15 yrs & 11 yrs & Yes & No & Yes & Yes \\
\hline Doug & 19 yrs & 8 yrs & Yes & Yes & Yes & No \\
\hline Nicky & 23 yrs & 14 yrs & No & Yes & Yes & No \\
\hline Matt & 13 yrs & 6 yrs & No & No & No & No \\
\hline Brad & 13 yrs & 6 yrs & Yes & Yes & Yes & Yes \\
\hline Naomi & 23 yrs & 9 yrs & Yes & Yes & Yes & No \\
\hline Rob & 38 yrs & 4 yrs & Yes & Yes & Yes & Yes \\
\hline Darcy & 15 yrs & 5 yrs & Yes & Yes & Yes & Yes \\
\hline
\end{tabular}




\section{APPENDIX B: INTERVIEW GUIDE}

\section{$\underline{\text { Interview Protocol }}$}

For the following questions, I'm going to ask you some questions about your teaching experiences. I would like you to keep your answers within the scope of one of your courses which you have taught both fully in-person and fully online.

1. Before discussing your course, please briefly tell me about your educational background and years of teaching experience both in-person and online.

2. Choose the course which has the most discussion. Additionally, the course should be at the 200-level (e.g. sophomore/second year) or higher.

A. Briefly describe this course.

- What sort of assignments, readings, and/or small group projects/discussion were involved in this course? Did you lecture? If so, was there discussion

included throughout the lecture?

\section{We will start by discussing your experiences with in-person delivery}

Think back to when you were teaching this course only in-person, before it was offered online.

A. What was the learning environment like?

- To what extent did you interact with students beyond lecturing, or delivering information?

- To what extent did students interact with one another?

- What elements of this course did you feel were most effective? Why?

B. Were any changes made to your in-person pedagogy/course delivery over time? 
- If there were changes, then why? Were the changes effective?

- If there were changes, did they affect student involvement?

C. Broadly, do you think the face-to-face nature of the course influenced learning? Why or why not?

- How so, and in what ways?

- Do you feel in-person discussion - both between you and the students and among themselves - influences learning?

- Discuss the non-verbal cues you get from students in this in-person course. Are they important? Why or why not?

4. Next I will ask you some questions about your experiences with the online delivery of this same course

Think back to when you began to deliver this course online.

A. Briefly describe this course

- What sort of assignments, readings, and/or small group projects/discussion were involved in this course?

* If you adapted these elements in some way for online delivery, why?

B. What was the learning environment like?

- To what extent did you interact with students beyond lecturing, or delivering information?

- To what extent did students interact with one another? 
- What elements of this course did you feel were most effective? Why?

C Were any changes made to your online pedagogy/course delivery over time?

- If there were changes, then why? Were the changes effective?

- If there were changes, did they affect student involvement?

D. Broadly, do you think the online nature of the course influenced learning?

- How so and in what ways?

- Do you feel online discussion - both between you and the students and among themselves - influences learning?

\section{Now I would like you to elaborate on the transition that you experienced as you shifted from an in-person to an online delivery of this same course}

A. Broadly, do you like teaching online? Why or why not?

- What, if any, were the major elements of your teaching experience that changed or adapted when you switched?

- If nothing changed, what allowed you to maintain your pedagogy?

- What have you liked about the change? Why?

- What have you not liked about the change? Why?

- How much time do you spend laboring in an online course as compared to an inperson one?

B. How do you know that your pedagogy has been effective? 
- How do you know students are understanding the course content?

- Discuss the change in non-verbal cues from the in-person course as compared to the online course. Has this been a factor in either your pedagogy or, as far as you can tell, student learning? Why or why not?

C. Do you feel students have a more positive online learning experience if you provide substantial guidance and assistance, or on the contrary, do they prefer to proceed through the course without much of your presence?

D. What has your experience been in dealing with the administration/bureaucracy during this process of transition? Dealing with your department during this process?

- As compared to your in-person compensation, do you feel you are compensated appropriately for teaching online?

* Has this been a factor in your decision to teach online?

- Have you been provided with enough support and opportunity for training to teach online?

- Do you feel your online teaching efforts are valued by your departmental/professional peers?

D. Describe the experience of the added scheduling flexibility that comes with an online course.

- What is your perception of how students deal with the added scheduling flexibility of online learning and their ability to do the work whenever they want?

* Are certain types of students better at adapting to online learning? If so, what do you see as these qualities, and do they relate to the student's autonomy? 
E. When you began teaching online, did you feel you possessed the skills needed to teach as effectively online as you did in-person? Why or why not?

- Based on your experience, what do you feel are the skills needed to effectively teach online?

- What do you know now about teaching online that you wish you had known then?

F. [If they say they use discussion] - Reflect on course discussion in your in-person course as compared to your online course.

- How is it similar? How is it different?

* Do you think the ability for students to respond at their own pace influences the quality of discussion? If so, in what ways?

- Did you ever have issues with student involvement in either setting?

* If so, how was this problem solved for each?

\section{I would like you to talk about any changes that occurred during this transition in terms of the way you see yourself as a teacher.}

- Do you have a persona or identity that is unique to your role as a teacher that is present when you teach or interact with students? If so, please describe.

* How is it the same or different when comparing in-person and online teaching?

- If it is different or has changed as a result of the online

classroom, why do you think that is?

- Compare the process of establishing a relationship with students in an in-person course and online course. 
- There are certain services - such as "Coursera" - which provide free and noncredentialed online courses delivered by esteem university professors. What are your feelings about this? Does this affect the way you see yourself as an educator?

\section{Finally, I would like to ask you some questions drawn from other relevant studies.} You may be repeating previous answers, but that is alright. [Drawing from Kanuka et. al (2002)]

- Tell me what new skill(s) you had to learn in order to use the [educational software] effectively for teaching? (technical)

- Tell me about classroom management? Follow up: How are these issues effectively resolved? (managerial)

- Describe to me the steps that you took to foster inter-learner interaction? (social)

- Tell me about your experiences with respect to the teaching/learning transactions when using the [educational software]?Follow-up: How does it differ from your face-to-face and/or prior distance learning instructional experiences? (pedagogical)

6. Do you have anything you would like to add? Can I contact you in the future if I have further questions? 


\section{APPENDIX C: CODEBOOK}

\section{Strategy developed for/during in-person teaching}

110 Using inquiry model

111 For inter-student interactivity

112 Using small groups to help students "lock in" knowledge

113 Avoiding lecture style

114 Learning together, "team teaching"

120 Using transmission model

121 Utilizing lecture style

122 Recognizing students want to learn from Prof, not from each other

130 Using blended model

131 Pairing down lectures

140 Utilizing technology

150 Taking advantage of smaller course size

151 For discussion

152 For "field trips", or off-campus projects

160 Requiring office hour visits

170 Teaching how one was taught

171 Not teaching how one was taught

180 Feeling committed to teaching in-person

190 Why important

191 One-on-one time allows Prof to catch students who are falling behind

192 Talking face-to-face develops relationships, sense of belonging

193 Too much lecturing is counter-productive to learning

194 In-person teaching performance is satisfying 


\section{Strategy developed for/by online teaching}

210 Utilizing technology

211 Matching curriculum to technology

212 Matching technology to curriculum

213 Using only basic tech in order to focus on course content

220 Coming to terms with the "saturated generation"

221 Understanding flexibility of online as the reason why students enrolled

222 Understanding students like videos, other tech resources

230 Giving more feedback than would in-person

240 Setting up course before term begins and then managing/facilitating

250 Skills needed

251 "Be human" even more so than in-person

252 Detail/task oriented

253 Learning the technology, or locating resources/help

253-1 Learning the "little tricks", which takes time

260 Understanding that if the deadlines are open that the end of the term will be workheavy

270 Managing online discussion

271 Hands on technique to ensure quality, satisfaction

272 Hands off technique as not to deter participation

280 Embracing "team teaching"

280a Feeling committed to teaching online

290 Why important

291A Establishing report in discussion board

\section{Changes in strategy/techniques}


310 Understanding online discussions as more like writing assignment

320R Resisting change and maintaining strategies

330A Understanding that online requires greater time commitment

331 Adjusting grading rigor

332 Needing to stay on top of discussion board because everything is recorded, more accountability for students and teacher

340 Constructing point system for online discussion to improve participation

\section{Adapting and transforming}

400A Treating in-person as more leisurely and online as more rigorous because online predicted as lower quality medium

401A Feeling greater responsibility to online students than in-person ones

420A Changing online pedagogy

421 To make workload more manageable for self

422 To make workload more manageable for students

423 To enhance interactivity

424 To lower expectations

430A Streamlining

431 Feedback techniques

432 Trimming down in-depth online discussion

440 Being detail oriented

450 Embracing new challenge

460 Engaging in student learning online

470R Difficulty envisioning teaching in a new way

480A Changing in-person pedagogy because of online teaching

490 Why important

491 Must enjoy challenge or it will seem like too much work 


\section{Support}

500A Understanding available resources

501R Not utilizing available resources

502R Lacking emotional support

510 Utilizing teaching assistants

511 For simple tasks like grading

512I For major tasks like team teaching

512-1 As primary managers of student inquiry

520 Support from peers

521A Emotional

522A Pedagogical

523R Lack of support from colleagues

\section{Rationalizing}

610 Increased expectation for students to be highly self-sufficient/independent

620 Preference for online

621 Because of scheduling convenience

622 Because in-person "performance" is anxiety inducing

623 Allows for other daily tasks

624 Enjoy the challenge

625 Students are more analytical, active

626 Students are more revealing, more personal

627 Students are more willing to be candid because of anonymity

628 Relationship with online students is stronger than with in-person students 629 Online courses take the power away from "manipulative charmers" 629a Online discussion is archived, making evaluation easier 
630 Preference for In-person

631 Because it is familiar

632 Because it is viewed as higher quality

642-1 Emphasis of nonverbal cues

642-2 Ability to meet with students in-person improves learning

642-3 More structure is good for younger students

642-4 More suitable for [social science discipline]

633 Unwilling to be challenged by new medium

634 Easier to recognize struggling students

635 Technology is unreliable

636 Online is lacking in oversight, quality control

638 Online courses don't fit with the typical western (transmission) model

639 Communicating in-person is different than online

639-1 In-person is more personal and interactive

640 No choice but to teach online in order to retain employment, competitive edge (Because of precarious employment with adjunct, assistant profs)

650 Spontaneity

651 Is important

652 Isn't important

700 Identity

700R Feeling threatened by relinquishing control

701A Willingness to change role

703 Feeling revitalized by teaching online

704 Feeling threatened by teaching online

\section{Evaluating Discussion}


810 Online discussion is higher quality

810-1 Because face-to-face discussion is painful for some

820 In-person discussion is higher quality

820-1 Because students need to learn oral comm skills

820-2 More conducive to difficult texts

820-3 Under-performing students will have greater benefit from in-person discussion

\section{Evaluating experience in retrospect}

910 Needing to retain an on-campus course to be satisfied with online learning

920 Real or imagined perception of lack of support leads to withdrawal of commitment to online

930 Online teaching is more work

86124 hour availability

862 More students per course

863 No pay rise for extra work

864 Harder to foster inter-personal interactivity

940 Online teaching is really management, not teaching ("gate keeper of learning”)

- R or A

\section{0 other}

\section{Story/Good quote}

\section{General codes}

$\mathbf{P}-\mathrm{PhD}$ or equivalent

M - Master's or equivalent

TIP1 - Teaching in-person for more than 4 years

TO1 - Teaching online for more than 4 years

DISC - Discipline 
TRANS - Transition course

A - Relates to acceptance of online / comfort with online

$\mathbf{R}$ - Relates to rejection of online / discomfort with online

I - Relates to impact on identity 